\title{
Influence of Pleistocene climatic oscillations on the phylogeography and demographic history of endemic vulnerable trees (section Magnolia) of the Tropical Montane Cloud Forest in Mexico
}

\author{
Yessica Rico ${ }^{\text {Corresp., } 1,2 \text {, }}$ M Ángel León-Tapia ${ }^{3}$, Marisol A. Zurita-Solís ${ }^{1}$, Flor Rodríguez-Gómez ${ }^{4}$, Suria Gisela Vásquez- \\ Morales $^{5}$ \\ ${ }^{1}$ Red de Diversidad Biológica del Occidente Mexicano, Instituto de Ecologia A.C., Patzcuaro, Michoacan, México \\ 2 CONACYT, Ciudad de México, Mexico \\ 3 Laboratorio de Sistematica Filogenética, Red de Biología Evolutiva, Instituto de Ecologia A.C., Xalapa, Veracruz, Mexico \\ 4 Departamento de Ciencias Computacionales, División de Electrónica y Computación, Centro Universitario de Ciencias Exactas e Ingenierías, Universidad \\ de Guadalajara, Guadalajara, Jalisco, Mexico \\ 5 Departamento de Biología, División de Ciencias Naturales y Exactas, Universidad de Guanajuato, Guanajuato, Guanajuato, Mexico \\ Corresponding Author: Yessica Rico \\ Email address: yessica.rico@inecol.mx
}

The Tropical Montane Cloud Forest (TMCF) is a highly dynamic ecosystem that has undergone frequent spatial changes in response to the interglacial-glacial cycles of the Pleistocene. These climatic fluctuations between cold and warm cycles have led to species range shifts and contractions-expansions, resulting in complex patterns of genetic structure and lineage divergence in forest tree species. In this study, we sequenced four regions of the chloroplast DNA (trnT-trnL, trnK5-matk, rpl32-trnL, trnS-trnG) for 20 populations and 96 individuals to evaluate the phylogeography, historical demography, and paleodistributions of vulnerable endemic TMCF trees in Mexico: Magnolia pedrazae (north-region), M. schiedeana (central-region), and M. schiedeana population Oaxaca (south-region). Our data recovered 49 haplotypes that showed a significant phylogeographic structure in three regions: north, central, and south. Bayesian Phylogeographic and Ecological Clustering (BPEC) analysis also supported the divergence in three lineages and highlighted the role of environmental factors (temperature and precipitation) in genetic differentiation. Our historical demography analyses revealed demographic expansions predating the Last Interglacial (LIG, $\sim 125,000$ years ago), while Approximate Bayesian Computation ( $\mathrm{ABC}$ ) simulations equally supported two contrasting demographic scenarios. The BPEC and haplotype network analyses suggested that ancestral haplotypes were geographically found in central Veracruz. Our paleodistributions modeling showed evidence of range shifts and expansions-contractions from the LIG to the present, which suggested the complex evolutionary dynamics associated to the climatic 
oscillations of the Pleistocene. Habitat management of remnant forest fragments where large and genetically diverse populations occur in the three TMCF regions analyzed would be key for the conservation of these magnolia populations. 
Influence of Pleistocene climatic oscillations on the phylogeography and demographic history of endemic vulnerable trees (section Magnolia) of the Tropical Montane Cloud Forest in Mexico

Yessica Rico ${ }^{1,2}$, M. Ángel León-Tapia ${ }^{3}$, Marisol A. Zurita-Solís ${ }^{1}$, Flor Rodríguez-Gómez ${ }^{4}$, Suria Gisela Vásquez-Morales ${ }^{5}$

${ }^{1}$ Red de Diversidad Biológica del Occidente Mexicano, Instituto de Ecología, A.C., Pátzcuaro, Michoacán, Mexico.

${ }^{2}$ CONACyT, 03940, Ciudad de México, Mexico.

${ }^{3}$ Laboratorio de Sistemática Filogenética, Biología Evolutiva, Instituto de Ecología A.C., Xalapa, Veracruz, Mexico

${ }^{4}$ Departamento de Ciencias Computacionales, División de Electrónica y Computación, Centro Universitario de Ciencias Exactas e Ingenierías. Universidad de Guadalajara, Guadalajara, Jalisco, Mexico.

${ }^{5}$ Departamento de Biología, División de Ciencias Naturales y Exactas, Universidad de Guanajuato, Guanajuato, Mexico

\section{Corresponding author:}

Yessica Rico ${ }^{1,2}$

${ }^{1}$ Red de Diversidad Biológica del Occidente Mexicano, Instituto de Ecología, A.C., Pátzcuaro, Michoacán, Mexico.

${ }^{2}$ CONACyT, 03940, Ciudad de México, Mexico.

yessica.rico@inecol.mx 
2

3

4

5

6

\section{Abstract}

The Tropical Montane Cloud Forest (TMCF) is a highly dynamic ecosystem that has undergone frequent spatial changes in response to the interglacial-glacial cycles of the Pleistocene. These climatic fluctuations between cold and warm cycles have led to species range shifts and contractions-expansions, resulting in complex patterns of genetic structure and lineage divergence in forest tree species. In this study, we sequenced four regions of the chloroplast DNA (trnT-trnL, trnK5-matk, rpl32-trnL, trnS-trnG) for 20 populations and 96 individuals to evaluate the phylogeography, historical demography, and paleodistributions of vulnerable endemic TMCF trees in Mexico: Magnolia pedrazae (north-region), M. schiedeana (centralregion), and $M$. schiedeana population Oaxaca (south-region). Our data recovered 49 haplotypes that showed a significant phylogeographic structure in three regions: north, central, and south. Bayesian Phylogeographic and Ecological Clustering (BPEC) analysis also supported the divergence in three lineages and highlighted the role of environmental factors (temperature and precipitation) in genetic differentiation. Our historical demography analyses revealed demographic expansions predating the Last Interglacial (LIG, $\sim 125,000$ years ago), while Approximate Bayesian Computation (ABC) simulations equally supported two contrasting demographic scenarios. The BPEC and haplotype network analyses suggested that ancestral haplotypes were geographically found in central Veracruz. Our paleodistributions modeling showed evidence of range shifts and expansions-contractions from the LIG to the present, which suggested the complex evolutionary dynamics associated to the climatic oscillations of the Pleistocene. Habitat management of remnant forest fragments where large and genetically diverse populations occur in the three TMCF regions analyzed would be key for the conservation of these magnolia populations. 


\section{Introduction}

Examining population genetic structure over historical spatial and temporal scales and its relationship with environmental changes is crucial for understanding species distributions and adaptations to the ongoing climatic changes (Scoble \& Lowe, 2010; Dalmaris et al., 2015). This information is extremely pertinent for vulnerable ecosystems of high species diversity and endemism in tropical regions. In Mexico, the Tropical Montane Cloud Forest (TMCF) covers less than $1 \%$ of the Mexican territory but has the highest biotic diversity per unit area that nearly accounts for $10 \%$ of the flora (Rzedowsky, 1978; Rzedowsky, 1996) and 12\% of the terrestrial vertebrates at the national level (Pineda et al., 2005; Sánchez-González et al., 2008). The TMCF usually occurs between 1200 to 2500 m.a.s.1., and with a patchy distribution in narrow strips along mountainous ranges (Rzedowsky, 1978; Alcántara et al., 2002). This ecosystem harbors highly specialized species dependent on microclimatic conditions associated to the presence of fog, high atmospheric humidity, and frequent rainfall (1000 to $5000 \mathrm{~mm}$ ) (Rzedowsky, 1978; Cruz-Cárdenas et al., 2012), which implies that the TMCF is very vulnerable to climate change (Ponce-Reyes et al., 2012).

The TMCF is a highly dynamic ecosystem, which has undergone frequent spatial changes in response to physical and climatic phenomena over geological time scales since the Neogene (Graham 1999; Rahbek et al. 2019), and with acute changes during the interglacial-glacial cycles of the Quaternary (Ramírez-Barahona \& Eguiarte, 2013; Guevara, 2020). During this period, the climatic variations between cold and warm cycles resulted in expansions and contractions of the TMCF due to the species dependency to the high atmospheric humidity (Ramírez-Barahona \& Eguiarte, 2013). These processes led to complex patterns of connectivity and fragmentation on species distributions, evolutionary adaptations to local environmental conditions and lineage divergence in plant and animal populations (Gutiérrez-Rodríguez et al., 2011; Ornelas et al., 2013; Venkatraman, 2019; Rahbek et al., 2019). Species demographic dynamics of the TMCF in response to the climatic oscillations of the Pleistocene in the Neotropics have been explained by two main precipitation models (reviewed in Ramírez-Barahona \& Eguiarte, 2013). The dry refugia model states that the cool conditions during the Last Glacial Maximum (LGM $\sim 23 \mathrm{ka}$ ) led to downslope migrations but the arid conditions in the lowlands resulted in species range contractions into glacial refugia. Subsequently in the Holocene ( 11.7- $8.3 \mathrm{ka})$ with the increase in temperature and humidity, populations expanded and re-colonized their former distribution ranges (Prance 1982; Ramírez-Barahona \& Eguiarte, 2013). According to the dry refugia and based on the distribution of endemic species and centers of endemism, Toledo (1982) postulated eight glacial refugia for forest species in Mexico: five adjacent to Central America and three in the drainage basin of the Gulf of Mexico in Veracruz and Oaxaca. Contrary to this model, the moist forests model states that the prevalence of humid conditions during the LGM lead to species migrations and expansions in the lowlands resulting in gene flow and wide range population connectivity. Later during the Holocene, the increase in temperature would have led to species range fragmentations and contractions into high altitude regions (Ramírez-Barahona \& 
77 Eguiarte, 2013). Each model would have led to different genetic signatures that can be contrasted

78

through analyses of phylogeography, demography, and ecological niche modeling (RamírezBarahona \& Eguiarte, 2013; Ornelas et al., 2019).

The most relevant genetic signatures according to the dry refugia are the genetic differentiation of populations from separate refugia due to limited gene flow during the LGM, a star-shaped allele genealogy of post-glacial expanding lineages and thus evidence of demographic expansions. Decline of genetic diversity away from refugial regions might also be expected by the occurrence of founder effects, whereas rare alleles would occur in high frequency in refugial populations (Excoffier et al., 2009; Gutiérrez-Rodríguez et al., 2011; Ramírez-Barahona \& Eguiarte, 2013). For the moist forests model, the stability of humid conditions during the LGM, which increased population connectivity, would have led to the maintenance of genetic diversity and homogenization of genetic variation with no clear geographical structuring (Twyford et al., 2012; Ramírez-Barahona \& Eguiarte, 2013). Demographic expansions and bottlenecks would be less likely to occur in large and continuous populations. Genetic evidence shows mixed support for both models (see Ramírez-Barahona \& Eguiarte, 2013) and for alternative hypotheses (see Ornelas et al., 2019; Salces-Castellano et al., 2021) in TMCF plant and animal species. Thus, gathering more data from other relevant endemic species is needed to better understand the complex dynamics on the evolution of the TMCF.

Trees are good models to evaluate demographic and phylogeographic patterns due to their long generation times that more likely preserve historical demographic signals. Moreover, they provide foundational habitat for many specialized endemic flora and fauna, being key elements of the TMCF biodiversity. Magnoliaceae is an ancient family of flowering trees and shrubs (subfamily divergence 78 - 47 Mya between the Cretaceous and the Eocene; RamírezBarahona et al., 2020) that had a continuous distribution in North America and Asia in the Eocene climatic optimum consistent with the Boreotropical flora (Dong et al., 2021). During the Neogene, magnolias migrated southward to warmer and wetter conditions in high valleys and mountain belts in Mexico, Central and South America (Hebda \& Irving, 2004). In Mexico, magnolias diversified with approximately 40 recognized species occurring in humid forests, such as the TMCF and other ecosystems (Vázquez-García et al., 2017). Fossil records of Magnolia seeds suggest they were abundant and widespread in the Northern Hemisphere in the Tertiary (Azuma et al., 2001), but currently many species are geographically restricted and with small population sizes (Rivers et al., 2016).

A representative magnolia species of the TMCF is Magnolia schiedeana Schltl., a narrow endemic from the late Miocene ( 10 Mya; Dong et al., 2021) occurring in the largest strip of the TMCF in the Sierra Madre Oriental from Hidalgo to central Veracruz (Vázquez-García, 1994) (Fig 1A). Due to its declining populations by anthropogenic threats of the TMCF, the species is listed as endangered in the IUCN The Red List of Mexican Cloud Forest Trees (GonzálezEspinosa et al., 2011), as vulnerable by IUCN The Red List of Magnoliaceae (Rivers et al., 2016) and protected under Mexico's domestic legislation (NOM-059, SEMARNAT 2010). Magnolia schiedeana was formerly considered to have a wider distribution, which included a 
117

118

119

120

121

122

123

124

125

126

127

128

129

130

131

132

133

134

135

136

137

138

139

140

141

142

143

144

145

146

147

148

149

150

151

152

153

154

155

156

northern-limit distribution in San Luis Potosí and Querétaro, and two disjoint distributions in eastern Guerrero and the Sierra de Juárez in northern Oaxaca (Vázquez-García, 1994). Taxonomic studies based on morphological characters showed that specimens in these regions were at least five different species (Guerrero: M. vazquezii Jiménez-Ramírez et al., 2007; $M$. guerrerensis; Cruz-Durán et al., 2008; Oaxaca: M. oaxacensis; Vázquez-García et al., 2012; $M$. zamudioi; Vázquez-García et al., 2013, and San Luis Potosí and Querétaro: M. pedrazae; Vázquez-García et al., 2013), but for some populations in Oaxaca (Metates in Santiago Comaltepec) the taxonomic identity remains unclear (A. Vázquez-García pers. comm.). Given their patchy distribution along mountainous ranges, vicariance has been hypothesized as an important mechanism in the evolution of many Mexican Magnolia (Vázquez, 1994). Despite that the TMCF harbors a considerable number of magnolia species that are threatened by habitat loss in Mexico (Vázquez-García et al., 2017; Rivers et al., 2016), the information about their population genetics and demographic dynamics associated to the climatic changes of the Pleistocene is almost lacking; this knowledge would shed light on the potential vulnerability of Magnolia trees to climate change from an historical perspective (D'Amen et al., 2013).

In this study we analyzed 20 populations and 96 individuals of $M$. pedrazae and $M$. schiedeana across their distribution in the Sierra Madre Oriental from San Luis Potosí to Veracruz, and one population in Santiago Comaltepec Oaxaca, which here we denote as $M$. schiedeana pop. Oaxaca. The distributions of these magnolia populations are within the largest strip of TMCF at the east of Mexico, which here we distinguish in three regions: north $(M$. pedrazae), central (M. schiedeana), and south (M. schiedeana pop. Oaxaca) (Fig. 1). Specifically, by sequencing four chloroplast DNA regions (trnT-trnL, trnK5-matk, rpl32-trnL, $\operatorname{trnS}$-trn $G$ ) our aims were to: (i) perform a phylogeographic approach to evaluate the historical signatures of the genetic divergence between $M$. pedrazae, M. schiedeana and M. schiedeana pop. Oaxaca, and (ii) evaluate whether demographic changes and past species distributions were influenced by the climatic oscillations of the Pleistocene.

\section{Material and methods}

Study species

Magnolia schiedeana is a perennial tree (> 200 years) up to 25 meters in height (RodríguezRamírez et al., 2020). The species flowers from April to June, has sexual reproduction but can reproduce clonally by sprouting from the base of the trunk (Vásquez-Morales et al., 2017). Seed dispersal occurs by birds and small mammals (Watanabe et al., 2002) and pollination by a specialist beetle Cyclocephala jalapensis (Dieringer \& Espinosa, 1994). Magnolia pedrazae occurs in remnant TMCF fragments in the north of Querétaro and southeast San Luis Potosí, whereas nothing is known about its biology. This species is listed as endangered by the IUCN Red List (Rivers et al., 2016), but not included under the Mexican domestic legislation.

Peer) reviewing PDF | (2020:12:56057:3:0:NEW 1 Aug 2021) 
157

158

159

160

161

162

163

164

165

166

167

168

169

170

171

172

173

174

175

176

177

178

179

180

181

182

183

184

185

186

187

188

189

190

191

192

193

194

195

196

\section{Sampling and DNA sequencing}

During February to November 2019, we collected leaf tissue samples from 15 remnant $M$. schiedeana populations from the states of Hidalgo, Puebla, and Veracruz. Moreover, we collected individuals from one locality in Santiago Comaltepec in Oaxaca, where its taxonomic identity is unclear. Additionally, we included four populations from M. pedrazae in Querétaro and San Luis Potosí, which samples were collected in a previous study in 2017 (Rico \& Gutiérrez-Becerril, 2019) for a total of 20 populations (Table 1, Fig. 1). We randomly collected young leaf samples from up to 10 adults or juvenile's trees and with a minimum separation between sampled trees of $10 \mathrm{~m}$. Leaves were preserved in sealable plastic bags containing silica gel until DNA extractions were performed. GPS coordinates were recorded for each locality. Permission to conduct our fieldwork was granted by the Mexican government (SEMARNAT SGPA/DGGFS/712/1062/18).

Genomic DNA from $20 \mathrm{mg}$ of dried tissue was extracted following the CTAB extraction protocol of Doyle \& Doyle (1987). We amplified four chloroplast (cpDNA) intergenic spacers: trnT-trnL (744 bp), trnK5-matk (789 bp), rpl32-trnL (624 bp) (Azuma et al., 2011), and trnS$\operatorname{trn} G$ (702 bp) (Shaw et al., 2005). PCR reactions were carried out using the MyTaq ${ }^{\text {TM }}$ DNA polymerase kit (BIOLINE, London, United Kingdom) following the conditions outlined in Rico \& Gutiérrez-Becerril (2019). Using the forward primers, PCR products were sequenced in MAGROGEN Inc. (Seoul, South Korea). A positive and negative control were included in each PCR plate to control for contamination. The quality of sequences was revised and edited in CHROMAS v2.6.5 (Technelysium Pty Ltd). We successfully sequenced 85 individuals, which unique sequences are available in NCBI GENBANK (www.ncbi.nlm.nih.gov) (NCBI accession numbers trnK5-matk: MW321790-321798, rpl32-trnL: MW321799-MW321808, trnS-trnG: MW321809-MW321812, trnT-trnL: MW321813- MW321827). Additionally, we used four cpDNA sequences from eight $M$. pedrazae individuals from San Luis Potosí and Querétaro and three M. schiedeana from Veracruz (CP population) obtained from Rico \& Gutiérrez-Becerril (2019) for a total of 96 individuals.

Phylogenetic and haplotype relationships

Sequences were aligned using MUSCLE v3.8.31 algorithm (Edgar, 2004) with default parameters and subsequently manually adjusted in MEGA X (Kumar et al., 2018). To reconstruct phylogenetic relationships, we included sequences from other Magnolia species available from GENBANK: Liriodendron chinese (KU170538), M. mexicana, Section Talauma (MN700657), M. ovata Section Talauma (MT293605), M. tripetala Section Rhytidospermum (AY727271, DQ826283, AY727517), M. acuminata Section Tulipastrum (MN990595), M. virginiana Section Magnolia (AB553858, AB553841, AB553861, AB553852), M. iltisiana Section Magnolia (MK210435, MK210442, MK210448, MK210453), and one sequence obtained in this study from M. pacifica Section Magnolia (Locality San Sebastián del Oeste, Jalisco). These species 
197

198

199

200

201

202

203

204

205

206

207

208

209

210

211

212

213

214

215

216

217

218

219

220

221

222

223

224

225

226

227

228

229

230

231

232

233

234

235

236

were chosen based on their closely phylogenetic relationships and L. chinese as the sister group of Magnolia (Azuma et al., 2011; Wang et al., 2020). The sequence from L. chinese was used as outgroup to root the tree. The four cpDNA sequences were concatenated using SEQUENCEMATRIX (Vaidya et al., 2011). The best substitution model fitting each marker was selected using the Akaike information criterion (AIC) in JMODELTEST v2.1.10 (Darriba et al., 2012). A consensus phylogenetic tree was obtained by Bayesian Inference (BI) using MRBAYES v3.2.2 (Huelsenbeck \& Ronquist, 2001), by performing two independent runs of three cold chains, one heated chain, and specifying 20,000,000 generations with sampled trees every 1,000 generations. We assessed convergence until we reached an average standard deviation of split frequencies below 0.01 . We discarded the first $25 \%$ of generated trees as burnin, and posterior probabilities (PP) were estimated from the posterior distribution of retained trees.

Genealogic relationships were obtained by constructing a median-joining (MJ) haplotype network in POPART (Leigh \& Bryant, 2015) for the concatenated cpDNA matrix of $M$. pedrazae $(\mathrm{n}=17), M$. schiedeana $(\mathrm{n}=74)$ and M. schiedeana pop. Oaxaca $(\mathrm{n}=5)$. All subsequent analyses were carried for this 96 individual's data set.

\section{Genetic diversity, differentiation, and phylogeographical structure}

For each sampled locality and for the three lineages, we estimated the mean haplotype $(H d)$ and nucleotide diversity ( $\pi$ ) using DNASP v6.12.03 (Rozas et al., 2017). Analyses of molecular variance (AMOVA) were performed to evaluate the amount of genetic variance and genetic differentiation $\left(F_{S T}\right)$ found in the following groupings: (1) no predefined groups, (2) populations in two lineages, M. pedrazae + M. schiedeana and M. schiedeana pop. Oaxaca, and (3) populations in three lineages, M. pedrazae, M. schiedeana and M. schiedeana pop. Oaxaca. AMOVAs were performed using the Tamura and Nei genetic distance and with 1000 permutations to determine the statistical significance of each partition as implemented in ARLEQUIN v3.5.2.2 (Excoffier \& Lischer, 2010). Evidence of phylogeographic structure was determined by contrasting the coefficients of population differentiation $G_{S T}$ and $N_{S T}$. A significantly higher $N_{S T}$ than $G_{S T}$ is evidence of a significant phylogeographical structure resulting from the occurrence of closely related haplotypes in populations (Pons \& Petit, 1996). These coefficients were obtained using PERMUT v2.0 (Pons \& Petit, 1996) with 10,000 permutations.

We used BAPS v5.3 (Corander et al., 2008) to determine the most likely number of genetic clusters using the clustering of linked loci module and the codon linkage model, appropriate for sequence data. First, with few replicates $(n=5)$ and three independent runs, we explored the likely number of genetic clusters from $K=2$ to 10 . By looking at the posterior probabilities and likelihood values, we observed that the most likely number of clusters was between 3 and 5 and thus the final analysis was carried out with two independent runs for $K=2$ to 5 with 10 replicates each. The most likely number of $K$ clusters was determined by its higher 
237 posterior probability and likelihood value. Additionally, pairwise $F_{S T}$ comparisons were

238 calculated in ARLEQUIN v3.5.2.2 with 1000 permutations to test for statistically significant

239

240

241

242

243

244

245

246

247

248

249

250

251

252

253

254

255

256

257

258

259

260

261

262

263

264

265

266

267

268

269

270

271

272

273

274

275

276 differences between lineages. Mantel correlations to test the effect of isolation by geographical distance (IBD) on $G_{S T}$ genetic and Euclidean distances was examined for the overall data set. Significance of the Mantel correlation was tested by permuting observations 1,000 times using the R library vegan 2.5.7 (Oksanen et al., 2015) (R core Team, 2020).

\section{Environmental differentiation on phylogeographic genetic clusters}

We implemented a Bayesian Phylogeographic and Ecological Clustering analysis (BPEC) in the BPEC v1.3.1 R package to reveal the geographical distribution of genetic clusters by considering genetic, geographical, and environmental data (Manolopoulou et al., 2011; Manolopoulou and Emerson 2012). This analysis assumes that population substructure is the result of migration events into new sites, which can be explained by geographical and ecological restrictions to gene flow (Manolopoulou et al., 2020). The test also provides measures of uncertainties for haplotype relationships and identify likely ancestral locations (Manolopoulou et al., 2020). We analyzed all cpDNA haplotypes, geographical locations, and current bioclimatic data extracted for each individual occurrence for 19 bioclimatic layers in 30 arc-seconds (Karger et al., 2017) downloaded from CHELSA (https://chelsa-climate.org).We discarded correlated bioclimatic variables ( $\mathrm{r} \geq 0.8$, see ecological niche modeling) and use the first two synthetic axes from Principal Components Analysis (PCA) as covariates. After several initial short runs, the final analysis was carried out with two maximum number of migrations and relaxation of the parsimony criterion not allowed (zero) to reach convergence. MCMC chains were run for 10 million steps with 10,000 posterior samples saved.

Additionally, statistical differences in the environmental space occupied for each lineage was tested on the two PC axes with a Multivariate Analysis of Variance (MANOVA) using the Pillai's trace as the test statistic (Nakazato et al., 2020). Moreover, we performed post hoc Tukey-HSD pairwise comparisons on each of the PC axes (Di Febbraro et al., 2017) using the base packages in $\mathrm{R}$.

\section{Historical demography}

To infer historical demographic changes, we used different methods. First, we estimated neutrality tests, Tajima's D (Tajima, 1989), Fu's F (Fu, 1997), and $R 2$ (Ramos-Onsins \& Rozas, 2002) with 1000 permutations using PEGAS R package (Paradis, 2010). Significant negative values of Tajima's D and Fu's F and positive $R 2$ values suggest rejection from neutrality and can be interpreted as population expansion. Second, we computed pairwise nucleotide mismatch distributions to contrast observed and expected distributions under a demographic growthdecline model using DNASP v6.12.03 (Rozas et al., 2017). A unimodal pairwise distribution is expected under a demographic expansion model, whereas a multimodal distribution would be 
277 expected for populations at demographic equilibrium (Harpending et al., 1998). Mismatch

278

279

280

281

282

283

284

285

286

287

288

289

290

291

292

293

294

295

296

297

298

299

300

301

302

303

304

305

306

307

308

309

310

311

312

313

314

315

316

distributions were tested with the sum of square deviations (SSD) and the Harpending's raggedness index (Hri) by implementing 1000 permutations in ARLEQUIN v3.5.2.2 (Excoffier $\&$ Lischer, 2010). Significant SSD and Hri values $(P \leq 0.05)$ indicate deviations from the sudden expansion model. Third, we used Bayesian skyline plots in BEAST v2.4.2 (Drummond \& Bouckaert, 2015) to assess effective population size $(\mathrm{Ne})$ changes across time. Two independent analyses were run, one for M. schiedeana $(\mathrm{n}=74)$ and one for M. pedrazae $(\mathrm{n}=17)$. We used the substitution model GTR+I as selected using AIC in JMODELTEST v2.1.10 (Darriba et al., 2012). Other parameters used were empirical base frequencies, a relaxed clock lognormal model, one run of 20 million generations, and trees and parameters sampled every 2000 iterations. The time axis was scaled with the substitution rates $1.59 \times 10^{-9}$ for chloroplast-wide, synonymous substitution rates described for most angiosperms (Wolfe et al., 1987). After the analysis, we viewed the log file in TRACER v1.7.1 (Rambaut et al., 2018) to ensure that effective sample sizes (ESS) for all priors were $>200$ (Drummond \& Bouckaert, 2015). The mismatch distribution plot and the Bayesian Skyline for M. schiedeana pop. Oaxaca was not possible due to small sample size.

Lastly, we used an Approximate Bayesian Computation (ABC) framework implemented in DIYABC v2.1 (Cornuet et al., 2008, 2014) to test for distinct competing demographic scenarios. According to the results of BAPS and BPEC, we contrasted five likely scenarios. At generation $\mathrm{t}_{0}$ (present), all scenarios had the three genetic lineages. The first scenario predicts that the three lineages diverge at the same time from a common ancestor $(\mathrm{Na})$ at time $\mathrm{t}_{2}$ and remained without demographic changes until time $\mathrm{t}_{0}$ (stable model). Scenarios 2,3 , and 4 , predict divergence at time $t_{1}$ between two of the lineages to subsequently merge the three lineages at time $t_{2}$ (divergence model). The difference between these three scenarios is the lineage diverging at time $t_{2}$, and subsequently the pair of lineages diverging at time $t_{1}$ (see results). Lastly, the fifth scenario predicts a split between M. schiedeana and M. schiedeana pop. Oaxaca at time $\mathrm{t}_{2}$, then both lineages merge with $M$. pedrazae at time $\mathrm{t}_{1}$ (admixture model). We considered these five scenarios as the most plausible given the observed relationships of divergence and admixture among the three lineages. Prior to the final run, we performed six runs to compare different parameter conditions. The run that we present in the results (see below) was the run with best adjusted parameters (Supplemental material). Each run was implemented with 2 million coalescent-based simulated datasets and different summary statistics.

For the final run and given the absence of information on the species population sizes, we used default priors. We generated three million coalescent-based simulated datasets for each of the five evolutionary scenarios considering the HKY model, and $N a, N 1, N 2$ and $N 3$ with a uniform prior distribution with a minimum of 10 and a maximum of 100,000 values for effective population sizes; the prior distribution of the timing of events was for $t_{1}$ and $t_{2} 100-100000$ generations respectively and considering a 10-year generation time (Vazquez-Morales \& Sánchez-Vélasquez, 2011). The set condition $\left(t_{2} \geq t_{1}\right)$ on the prior time distribution was added up to avoid incongruences in the simulated genealogies. For the final run, we used the following summary

Peer] reviewing PDF | (2020:12:56057:3:0:NEW 1 Aug 2021) 
317

318

319

320

321

322

323

324

325

326

327

328

329

330

331

332

333

334

335

336

337

338

339

340

341

342

343

344

345

346

347

348

349

350

351

352

353

354

355

356

statistics: (1) For the three groups: Number of segregating sites, mean pairwise differences, and mean number of the rarest nucleotide at segregation sites; (2) For the 1-2, 1-3 and 2-3 groups: Number of segregating sites and $\mathrm{F}_{\mathrm{ST}}$. We used a prior distribution of mean mutation rates of $1.59 \times$ $10^{-9}$ for the chloroplast (Wolfe et al. 1987). We used the default parameters for the mutation model section. Scenario posterior probabilities were evaluated using a logistic regression on the $1 \%$ of simulated datasets nearest to the observed data (Fontaine et al., 2013). For the best-supported scenario, we performed a model checking procedure by applying a PCA on test statistic vectors to visualize the fit between the observed and simulated datasets. Confidence of the scenario choice was assessed by simulating 500 pseudo-observed datasets (PODs) under each scenario to calculate Type I and II error rates. Finally, for the best-supported scenario, we obtained point estimates for demographic and temporal parameters using local linear regression on the $1 \%$ of simulations nearest to the observed dataset (Cornuet et al., 2008, 2014).

\section{Present and past distribution ecological niche modeling}

Due to the taxonomic uncertainty for Magnolia species, we only used the occurrences from specimens of M. schiedeana, M. pedrazae, and samples from Oaxaca collected in this study (Supplemental Table S1). We used these occurrences because they have the quality and spatial accuracy to produce models with ecological plausibility (Galante et al., 2018). To avoid sampling biases, the occurrences were spatially thinned at three kilometers as a larger radius would have significantly reduce the final number of occurrences; this was carried in the SPTHIN v0.1.0.1 R package (Aiello-Lammens et al., 2015). Additionally, a second data set was built with occurrences downloaded from the Global Biodiversity Information Facility (GBIF; http://www.gbif.org/), but due to the likely uncertainty of some of these records, we also included localities reported in previous studies, such as herbaria specimens of M. schiedeana (Vásquez-Morales et al., 2014, 2017). Specimens with insufficient locality information were discarded; all occurrences were thinned at five kilometers due to a higher density of occurrences than the training data set. The first data set included 26 occurrences used for building the niche model and the second data set included 50 occurrences used for testing the models. As variable predictors, we used the 19 bioclimatic layers in 30 arc-seconds from CHELSA because these layers have a better performance than other layers commonly used and can increase the accuracy of species range predictions (Karger et al. 2017). The environmental layers were delimited to several polygons of the level II ecoregions of North America downloaded from the United States Environmental Protection Agency (https://www.epa.gov/); the ecoregions were: Mexican high plateau, eastern Sierra Madre Oriental, west humid coastal plains and hills of the Gulf of Mexico, southern Sierra Madre del Sur, east of the Mexican Plateau, east of the Trans Mexican Volcanic Belt, and south of the North American deserts. These areas were chosen as likely accessible areas.

Values from the 19 current bioclimatic layers were extracted from individual occurrences and Pearson's correlations threshold of 0.8 and 0.7 were performed with the occurrences sites to minimize variable redundancy using NTBOX v0.1.4.5 R package (Osorio-Olvera et al., 2020). 
357 The final uncorrelated variables according to the 0.8 Pearson's threshold were: annual mean

358

359

360

361

362

363

364

365

366

367

368

369

370

371

372

373

374

375

376

377

378

379

380

381

382

383

384

385

386

387

388

389

390

391

392

393

394

395 temperature (BIO1), isothermality (BIO3), temperature seasonality (BIO4), temperature annual range (BIO7), annual precipitation (BIO12), precipitation of the driest month (BIO14), precipitation seasonality (BIO15), and precipitation of the warmest quarter (BIO18). For the 0.7 threshold, BIO4 was the only variable discarded. To have a better balance between the number of occurrences and the number of bioclimatic variables, the niche model was built with the 0.7 correlation threshold (Dormann et al., 2012) under the maximum entropy algorithm (Phillips et al., 2017) in MAXENT v3.4.1 using the KUENM v1.1.1 R package (Cobos et al., 2019). Some levels of model complexity were evaluated by varying the regularization multiplier (RM) from 0.5 to 10 every 0.5 , and feature classes linear $(\mathrm{L})$, quadratic $(\mathrm{Q})$, product $(\mathrm{P})$, and threshold $(\mathrm{T})$ in four fixed combinations: L, LQ, LQP, and LQPT, which resulted in 80 candidate niche models. The hinge $(\mathrm{H})$ feature was not considered to simplify the niche model for subsequent transferability. The evaluation was made using 10,000 background points, five percent of training data omission rate (OR), 20\% for bootstrapping to calculate the partial Receiver Operating Characteristic (pROC) with 10000 iterations. The best model was selected considering the statistically significant models, and the lowest values of corrected Akaike information criterion (AICc) and inspecting the OR. The average niche model with the best parameters was built and projected to the same area using ten replicates of bootstrap and the logistic output format.

To construct the paleodistributions, the 19 variables used for the current model were downloaded, and the features of the best current niche model were projected to the same area into past four scenarios based on the Community Climate System Model simulations. The scenarios assessed were: mid-Holocene (MH; 8.3 - 4,000 years ago (ya)) at $30 \mathrm{sec}$ downloaded from WORLDCLIM (http://www.worldclim.com), early-Holocene (EH; 11.7 - 8,000 ya) at 2.5 min resolution (Fordham et al., 2017) downloaded from PALEOCLIM (http://www.paleoclim.org/), Last Glacial Maximum (LGM; 23 - 14,000 ya) at $30 \mathrm{sec}$ downloaded from CHELSA (Karger et al., 2018), and Last Interglacial (LIG; $120-140,000$ ya) at $30 \mathrm{sec}$ (Otto-Bliesner, 2006) downloaded from WORLDCLIM. The resolution of EH was downscaled to $30 \mathrm{sec}$. The extent and dimension of all scenarios were matched with those of the current model to make further comparisons and avoid alterations in predictions (Randin et al., 2009). The layer sources were chosen to have the original $30 \mathrm{sec}$ resolution for most scenarios.

To evaluate the risk of extrapolating to non-analogous conditions (novel environments) in each past scenario, we compare the calibration area (i.e., reference data) with the four past scenarios (i.e., projection data) by quantifying the extrapolation due to covariate range (NT1) and correlation change (NT2) with the ExDet method (Mesgaran et al., 2014) implemented in NTBOX v0.1.4.5. Transferability was carried out using three methods of extrapolation: free extrapolation, extrapolation and clamping, and no extrapolation. The niche overlap was calculated using the Schoener's D metric in the geographic space (Warren et al., 2008), which D values range from 0 (no overlap) to 1 (identical predictions). Finally, we calculated Pearson

Peer) reviewing PDF | (2020:12:56057:3:0:NEW 1 Aug 2021) 
396

397

398

399

400

401

402

403

404

405

406

407

408

409

410

411

412

413

414

415

416

417

418

419

420

421

422

423

424

425

426

427

428

429

430

431

432

433

434

correlations between model predictions. All procedures were performed in the R libraries raster v3.3-13 (Hijmans, 2020) and ENMeval v0.3.0 (Muscarella et al., 2014).

\section{Results}

\section{Phylogenetic and haplotype relationships}

The phylogenetic cpDNA concatenated matrix including sequences from other Magnolia species used as outgroup consisted of 106 individuals with a total length without gaps and missing data of 2,803bp. The aligned matrix consisted of 147 polymorphic and 35 informative sites. The bestfitting model of sequence evolution was GTR + I. The BI tree showed that M. iltisiana, $M$. pacifica, M. pedrazae, M. schiedeana and M. schiedeana pop. Oaxaca formed a polytomy with a low support $(\mathrm{PP}=0.5)$. Samples from $M$. pedrazae and $M$. schiedeana were not monophyletic, but samples from M. schiedeana pop. Oaxaca were grouped within well-supported subclade (PP =1) (Fig. 2A).

For the haplotype network, the concatenated cpDNA matrix had a total length of 2,858 bp excluding gaps and missing data for 96 individuals. There were 47 polymorphic sites and 18 informative sites. A total of 49 haplotypes were identified (Table 1). Haplotype relationships revealed only two shared haplotypes (H01 and H02) between M. pedrazae (north) and $M$. schiedeana (central), and none with M. schiedeana pop. Oaxaca (south). Overall, few haplotypes were shared among populations, but most of them diverged by one mutational change ( $\max 5$ mutation steps between $\mathrm{H} 02$ and $\mathrm{H} 13$ from M. schiedeana). The most frequent haplotypes (H02 and $\mathrm{H} 03$ ) were present in 7 out of $15 \mathrm{M}$. schiedeana populations, and present only (H02) in one population from $M$. pedrazae in San Luis Potosí. Haplotype connections between M. pedrazae and M. schiedeana occurred through haplotypes from Veracruz populations (MI (H36), FXC (H22 and H23)), while the connection of the three M. schiedeana pop. Oaxaca haplotypes were through a missing haplotype that tied a haplotype from M. schiedeana in Hidalgo (GO) and $M$. pedrazae from San Luis Potosí and Querétaro (CS, JH) (Fig. 2B).

\section{Genetic diversity, phylogeographic structure and environmental differentiation}

Genetic diversity was high for $M$. schiedeana $(H d=0.923 ; \pi=0.001)$ and $M$. pedrazae $(H d=$ $0.95 ; \pi=0.0009)$ and moderate for $M$. schiedeana pop. Oaxaca $(H d=0.7 ; \pi=0.0007)$. At the level of populations, the most genetically diverse were MY and AC in Veracruz for $M$. schiedeana, and CS in San Luis Potosí for M. pedrazae (Table 1). The AMOVA with no groups defined a priori showed that the genetic variance explained among populations was $32.5 \%\left(F_{S T}=\right.$ $0.33, P<0.001)$. When populations were grouped in two lineages $(M$. pedrazae $+M$. schiedeana, and M. schiedeana pop. Oaxaca), a much higher proportion of the genetic variance 
435

436

437

438

439

440

441

442

443

444

445

446

447

448

449

450

451

452

453

454

455

456

457

458

459

460

461

462

463

464

465

466

467

468

469

470

471

472

473

474

and thus genetic differentiation was observed $\left(57.6 \%, F_{C T}=0.58, P<0.001\right)$, whereas when three lineages were considered (M. pedrazae, M. schiedeana and M. schiedeana pop. Oaxaca), a slightly lower proportion of the genetic variance and genetic differentiation were observed relative to the two lineages grouping $\left(48.3 \%, F_{C T}=0.48, P<0.001\right)$ (Table 2). Pairwise $F_{\mathrm{ST}}$ comparisons showed that the highest differentiation was between $M$. schiedeana and $M$. schiedeana pop. Oaxaca $\left(F_{\mathrm{ST}}=0.67, P=0.001\right)$, and the lowest between $M$. schiedeana and $M$. pedrazae $\left(F_{\mathrm{ST}}=0.42, P=0.001\right)$ (Supplemental Table $\left.\mathrm{S} 2\right)$. We found a weak and significant pattern of IBD for the whole data set $(\mathrm{r}=0.31, P=0.022)$, but which significant effect disappeared when $M$. schiedeana pop. Oaxaca was excluded from the analysis $(\mathrm{r}=0.015, P=$ 0.46). Results from PERMUT revealed a significant phylogeographical structure $\left(G_{S T}=0.048\right.$ and $\left.N_{S T}=0.364, P<0.05\right)$.

BAPS revealed four likely clusters $(K=4, \log$ marginal likelihood $=-201.9484, \mathrm{PP}=$ 0.72 ): cluster one was mostly formed by $M$. pedrazae, cluster 2 mostly with $M$. schiedeana, cluster 3 with only one individual from GO, and cluster 4 with M. schiedeana pop. Oaxaca and MI population; these observed clusters thus corresponded to the three TMCF regions (Fig 2C). Similarly, BPEC showed three phylogeographic clusters with high membership posterior probabilities for most haplotypes ( $\mathrm{PP}=0.80$ to 0.99 ). The three main clusters also corresponded to M. pedrazae, M. schiedeana and M. schiedeana pop. Oaxaca (Fig. 2D). However, uncertainty of cluster location was evident for the M. schiedeana pop. Oaxaca, as some M. schiedeana haplotypes (H10, H17, H22, H23, H36, H40) from Veracruz (except H10 from Puebla) were assigned to M. schiedeana pop. Oaxaca (Supplemental Fig S1). Ancestral locations were in central Veracruz (Supplemental Fig S1). The environmental variation of the two PCs revealed statistically significant differences among the three lineages (Pillai's trace $=0.78, \mathrm{~F}_{2,93}=30.21$, $P<0.001)$. Tukey-HSD revealed statistically significant pairwise differences between the three lineages along the PC $1(38.3 \% P<0.001)$; variable contribution was: temperature annual range $(\mathrm{BIO})=27.3 \%$, precipitation seasonality $(\mathrm{BIO} 15)=24.2 \%$, temperature seasonality $(\mathrm{BIO} 4)=$ $21.3 \%$ and precipitation of the driest month $(\mathrm{BIO} 14)=20.3 \%)$. For the PC $2(28.4 \%)$ statistically significant differences were observed between $M$. schiedeana and $M$. pedrazae $(P<0.001)$ and between $M$. schiedeana and $M$. schiedeana pop. Oaxaca $(P<0.001)$; variable contribution was: annual precipitation $(\mathrm{BIO} 12)=34.6 \%$, precipitation of the warmest quarter $(\mathrm{BIO} 18)=34.2 \%$, and precipitation of the driest month $(\mathrm{BIO} 14)=13.2 \%$ (Fig. 2E-F).

\section{Historical demographic changes}

Tajima's D and Fu's F showed statistically significant negative values, and positive significant $R 2$ values for M. schiedeana, indicative of population expansion, while for M. pedrazae and $M$. schiedeana pop. Oaxaca, neutrality tests were non-significant (Table 3). Mismatch distributions for the observed and expected values for M. pedrazae and M. schiedeana, fit with the expectation of recent demographic expansions (Fig. 3A and 3B). These mismatch distributions were not rejected by the SSD and Hri tests (Table 3). Bayesian skyline plots of $N_{\mathrm{e}}$ through time showed an 
475

476

477

478

479

480

481

482

483

484

485

486

487

488

489

490

491

492

493

494

495

496

497

498

499

500

501

502

503

504

505

506

507

508

509

510

511

512

513

514

increase in effective population size over time for M. pedrazae at $\sim 200,000$ years ago (Fig. 3C), and for M. schiedeana between $\sim 300,000$ to 250,000 years ago (Fig. 3D), both predating the LGM.

The ABC simulations provided the best support for scenario 2 and scenario 5 (PP: 0.35 , 95\% CI: $0.342-0.366$ and PP: $0.36,95 \%$ CI: $0.347-0.373$, respectively) that performed better than the other three scenarios. Confidence estimates for scenario choice indicated that Type I errors for the best-supported scenarios were high (scenario 2: 0.62 and scenario 5: 0.64) but Type II errors were higher for scenario $5(0.73)$ relative to the scenario $2(0.51)$. As statistically there is no way to discriminate which of the two is the best scenario when both are equally likely (Bertorelle et al., 2010), we considered scenarios 2 and 5 as the most likely, although biologically they are contrasting (Fig. 4). Assuming a 10-year generation time, under scenario 2 and 5, the posterior mean parameter estimates indicated that the divergence $\left(\mathrm{t}_{2}\right)$ of $M$. schiedeana pop. Oaxaca from $M$. schiedeana occurred 82,300 (CI: 37.7-99.2) and 84,800 (CI: 41.7-99.4) years ago, respectively, which fits the LIG. Under scenario 2, the mean estimated divergence time of M. schiedeana and $M$. pedrazae was 35,000 (CI: 3.5-81.3) years ago before the LGM, while for scenario 5, the admixture among the tree lineages was estimated around 22,900 (CI: 1.7-72.7) years ago, during the LGM. However, confidence intervals were large for both scenarios, going from the LIG until very recent times (Supplemental Table S3 and Fig S2).

\section{Present and past species distributions}

The evaluation showed that the best niche model has a significant pROC $(P<0.001), 0.22$ OR, and 1617.9 AICc with the LQP features and 1.0 RM. This niche model was constructed with the following variables and permutation importance: BIO14 (39\%), BIO1 (34\%), BIO3 (10.7\%), $\mathrm{BIO} 7$ (6.2\%), BIO18 (4.8\%), BIO12 (2.7\%), and BIO15 (2.7\%).

The present niche model geographically projected showed the highest suitability values mainly at the center of Veracruz and for scattered areas towards the northern periphery, while Oaxaca showed moderate suitability values (Fig. 5A-B). The extrapolation detection analyses showed that the percentage of non-analogous conditions for each past scenario were: NT1 $(34.5 \%)$ and NT2 (3.24\%) for MH, NT1 (4\%) and NT2 (0.25\%) for EH, NT1 $(8.4 \%)$ and NT2 $(0.13 \%)$ for LGM, and NT1 $(24.9 \%)$ and NT2 $(0.19 \%)$ for LIG. The NT1 and NT2 extreme values were low (-2.4 and -7.9) confirming low extrapolation risk (Supplemental Fig S3). On the other hand, the three methods of extrapolation for the four past scenarios showed similar predictions with only slight variations, therefore, only the projections with no extrapolation are shown.

Paleodistributions to the $\mathrm{MH}$ revealed that high suitability values were present in scarce areas at central east of the TMCF (Puebla and Veracruz) (Fig. 5C), whereas for the EH much higher suitability values were found across most of the species ranges from north (San Luis Potosí), central (Veracruz) and south (Oaxaca) (Fig. 5D). During the LGM high suitability habitat was present in two disconnected areas, one in central Veracruz and the other in south of 
515 Oaxaca (Fig. 5E). During the LIG, a thin strip with high suitability was restricted mostly at the 516 central east (Veracruz and Puebla) (Fig. 5F). The Schoener's D and Pearson correlation between 517 the present and past species projections were $\mathrm{MH}: \mathrm{D}=0.2$ and $\mathrm{r}=0.24, \mathrm{EH}: \mathrm{D}=0.47$ and $\mathrm{r}=$ 5180.56 , LGM: $\mathrm{D}=0.48$ and $\mathrm{r}=0.53$, and LIG: $\mathrm{D}=0.49$ and $\mathrm{r}=0.69$, which highlights the 519 differences between the present and past niche suitability species distributions.

520

521

522

523

524

525

526

527

528

529

530

531

532

533

534

535

536

537

538

539

540

541

542

543

544

545

546

547

548

549

550

551

552

553

554

\section{Discussion}

In this study we employed analysis of phylogeography, historical demography and paleodistributions to understand how climatic oscillations of the Pleistocene have shaped geographical patterns of genetic diversity in endemic Magnolia trees of the largest remaining TMCF strip in Mexico. Based on four cpDNA sequences, we found evidence of three genetic lineages and signatures of demographic expansions, while past species distributions showed range expansions and contractions during the interglacial-glacial cycles of the Pleistocene, which suggest the strong role of climatic and/or environmental factors influencing the complex evolutionary dynamics of these Magnolia lineages.

\section{Genetic differentiation among TMCF regions}

The MJ network, BAPS, and BPEC analyses jointly revealed three genetic clusters that showed a significant phylogeographical structure. The MJ network revealed 10 haplotypes exclusive to the north (M. pedrazae), 34 haplotypes to the central (M. schiedeana), and three to the south ( $M$. schiedeana pop. Oaxaca) of the TMCF. Only two haplotypes were shared between the north and central lineages, one of which was widespread in the central region but not in the north. None of the haplotypes were shared between M. schiedeana pop. Oaxaca. Similarly, AMOVAs showed that the amount of genetic variance explained among these three lineages was moderate (48\%), but it was considerable higher (58\%) when only two lineages (M. pedrazae + M. schiedeana and M. schiedeana pop. Oaxaca) were considered. In contrast to these results, the Bayesian phylogenetic tree did not resolve the monophyly of the three lineages as all samples formed a polytomy with other closely related Magnolia species (M. iltisiana and M. pacifica). The lack of resolution of the phylogenetic relationships based on the cpDNA may be due to its slow-evolving mutation rate (Richardson et al., 2013) and incomplete lineage sorting, which has been found in other magnolias (Kikuchi \& Osone, 2021). On the other hand, the chloroplast DNA in magnolias is maternally inherited (Tobe et al., 1993) and thus reflect patterns of seed-mediated gene flow. Bird dispersal as likely occurs for M. schiedeana (Watanabe et al., 2002) may provide gene flow at large spatial scales thus connecting populations over large distances (Newton et al., 2008; Setsuko \& Tomaru, 2009).

The geographical circumscription of M. schiedeana has changed over time as the result of recent species designations based on morphological characters (Jiménez-Ramírez et al., 2007; 
555 Cruz-Durán et al., 2008; Vázquez-García et al., 2012; Vázquez-García et al., 2013), while 556 molecular taxonomic studies are lacking. A population genetic study by Rico \& Gutiérrez557 Becerril (2019) pointed that the species designation of M. pedrazae was not evident based on 558 observed patterns of genetic differentiation estimated with nuclear microsatellites that showed 559 strong to moderate differentiation across populations irrespective of their species identity. 560 Although few populations of $M$. schiedeana were included in the study. For populations in 561 Oaxaca, specifically in Santiago Comaltepec, the taxonomic designation remains unclear. Our 562 results clearly support the genetic divergence of $M$. schiedeana pop. Oaxaca, which likely has

563

564

565

566

567

568

569

570

571

572

573

574

575

576

577

578

579

580

581

582

583

584

585

586

587

588

589

590

591

592

593

594 remained isolated for a longer time according to the $\mathrm{ABC}$ analysis and the largest differentiation of this population shown by the pairwise $F_{S T}$ estimates. Due to our limited sampling for Oaxaca, we cannot confirm if this population represents a distinct taxonomic unit. A formal taxonomic delimitation study between $M$. schiedeana and recent designated species is outside the scope of this work. Species designation and delimitation remain controversial topics in biology (De Queiroz, 2007) and the taxonomy of Neotropical magnolias is a good example of the complexity to circumscribe species (Vázquez-García, 1994; Aldaba-Núñez et al., 2021). However, as recently suggested by Huang (2020), to clarify whether population subdivision or speciation is warranted from an evolutionary perspective, we need a better understanding of the sources that generate and maintain structured intraspecific variation that may lead to interspecific divergence. In this study we contribute towards understanding the historical processes that have shaped pattens of genetic diversity in these Magnolia populations. Additional morphological, molecular (nuclear markers) and ecological data and broader population sampling is needed to further clarify species delimitation of the Magnolia section.

\section{Effects of the Pleistocene in the phylogeographical structure and demographic changes}

Divergence among Neotropical magnolias is thought to occur mainly by vicariance given by the archipelago-type distribution of the TMCF (Vázquez-García, 1994; Jiménez-Ramírez et al., 2007; Cruz-Durán et al., 2008). Phylogeographical studies of tree species of the TMCF in Mexico have shown patterns of allopatric divergence caused by major biogeographical barriers, such as the Trans-Mexican Volcanic Belt (TMVB) (Liquidambar styraciflua, Ruiz-Sánchez \& Ornelas, 2014) and for the Isthmus of Tehuantepec (Palicourea padifolia, Gutiérrez-Rodríguez et al., 2011) during the Pliocene to mid-Pleistocene. Specifically, the TMVB is a volcanic chain that horizontally splits Mexico into north and south, and which has profound impacts on the historical differentiation across multiple taxa, including flora and fauna (Mastretta-Yañes et al. 2015). The diversification of the Magnolia section has been estimated around 32.4 Mya at the early Oligocene, while the divergence of $M$. schiedeana can be placed at $\sim 10$ Mya during the late Miocene (Dong et al., 2021). This epoch was marked by the second pulse of volcanism from west to east of the TMVB ( 11 to 7 Mya, Ferrari et al., 2012), and by warm and humid conditions (Frigola et al., 2018). However, the estimated divergence based on the ABC analyses was far more recent; scenario 2 suggests that M. schiedeana pop. Oaxaca is the oldest lineage 
595

596

597

598

599

600

601

602

603

604

605

606

607

608

609

610

611

612

613

614

615

616

617

618

619

620

621

622

623

624

625

626

627

628

629

630

631

632

633

634

that diverged from a common ancestor around 80,000 years ago, while scenario suggests that $M$. schiedeana and M. schiedeana pop. Oaxaca diverged from a common ancestor around 85,000 years ago, both estimations of divergence events occurred during the warm and wet conditions of the LIG. The BPEC analyses suggested that ancestral haplotypes were in central Veracruz, and this coincides with the past niche projections where the largest extent of optimal habitat occurred in this region during the LIG. Our small sample size for M. pedrazae and M. schiedeana pop. Oaxaca, and the large confidence intervals obtained from demographic analyses, suggest that our divergence and demographic expansion dates should be interpreted cautiously. Moreover, the ABC simulations showed as equally likely two contrasting demographic scenarios, one that suggested the divergence of the three lineages, and the other their admixture, which we could not discriminate given their high type I and II error rates.

Neutrality tests showed demographic expansions for M. schiedeana, while the mismatch distributions and the star-shape topology of the haplotype network suggested that M. pedrazae also underwent a demographic expansion. These observations agreed with the Bayesian skyline plots that showed demographic expansions for M. schiedeana $(\sim 250,000$ ya) and M. pedrazae $(\sim$ 200,000 ya), both predating the LIG. Demographic growth was also suggested by the ABC simulations, which showed an increase of population sizes for both scenarios after the divergence from a common ancestor around the LIG (Supplemental Table S3). Our paleodistribution models during the last $\sim 120,000$ years ago highlighted complex population dynamics characterized by range shifts, contractions-expansions. Specifically, during the warmer conditions of the LIG, suitable habitat was mainly restricted to central Veracruz and Puebla, Then, during the LGM, suitable habitat remained in Veracruz and Puebla, but also was present in south of Oaxaca, although both areas were disconnected. Later during the early Holocene, suitable habitat considerably expanded northwards, from Oaxaca to Veracruz and San Luis Potosí. However, in the mid-Holocene suitable habitat was drastically reduced to small areas in Puebla and Veracruz, and then expanded in the present. Although our past scenarios were well supported and showed low extrapolation risk, caution must be warranted considering the low number of occurrences used to build the niche model and that these hypotheses are based on a single GCM, specifically in the LGM in which different GCM could give contrasting results (Guevara et al. 2018). Increasing the number of occurrence records through field explorations and taxonomic studies in these taxa would further improve the accuracy of species distribution models.

The glacial refugia proposed by Toledo (1982), suggests that Sierra de Juárez in Oaxaca and Córdoba in Veracruz were secondary refugia for tropical forest species during the LGM due to their high humid conditions. For instance, the Sierra de Juárez in Santiago Comaltepec is recognized as one of the TMCF regions where atmospheric humidity is the highest (Gual-Díaz \& González-Medrano 2014). The secondary refugia suggested by Toledo coincides with the locations of high suitable habitat predicted for the LGM, one towards the south of Oaxaca and the other in central Veracruz, although suitable habitat during the LGM increased relatively to the LIG, which the refugia model do not predict. As there is no conclusive evidence unambiguously supporting either of the two precipitation models, further investigations are 
635

636

637

638

639

640

641

642

643

644

645

646

647

648

649

650

651

652

653

654

655

656

657

658

659

660

661

662

663

664

665

666

667

668

669

670

671

672

673

674

needed by incorporating more samples (Oaxaca) and highly variable nuclear markers for testing these and other alternative hypotheses (vulcanism in the TMVB), which could elucidate the complex evolutionary history of these lineages.

According to our genetic data, Magnolia schiedeana pop. Oaxaca likely remained isolated from the other two lineages before and during the LGM, as suggested by the lack of shared haplotypes among them and the evidence of its oldest divergence relative to the other two lineages. During the early Holocene $(\sim 11.7$ ya) the increase in temperature and humidity could have facilitated the range expansion from the south-central towards the northern periphery. Colonization of the northern periphery may have occurred by long-distance dispersal as suggested by the lack of IBD between M. pedrazae and M. schiedeana, and the retention of ancestral polymorphism in the cpDNA. The star-like network topology, the high haplotype diversity, but the low nucleotide diversity suggests the most recent recolonization of the northern periphery of the TMCF. The range contraction-expansion from the mid-Holocene $(\sim 8.3 \mathrm{ya})$ to the present suggested by the climatic models, may explain the weaker genetic divergence between $M$. pedrazae and M. schiedeana as there is no major geographical barriers that could explain their genetic divergence. Moreover, the BPEC analysis suggested that genetic divergence can also be shaped by environmental factors. Specifically, the environmental PCAs revealed significant differences among the three lineages, which mainly can be attributed to annual temperature range and precipitation seasonality. The TMCF of Mexico are composed of highly heterogenous forest that can vary markedly in environmental conditions (Gual-Díaz \& GonzálezMedrano 014). Local environmental differences have been suggested to generate the large intraspecific morphological variations observed across populations of M. schiedeana (Vite et al., 2016; Rodríguez-Ramírez et al., 2020). This environmental heterogeneity may have led to differential habitats preferences and thus to divergence by ecological factors, a potential hypothesis that could be tested in the future.

\section{Conservation implications}

The TMCF is one of the most threatened ecosystems due to the strong anthropogenic pressures for land conversion and the predicted changes in temperature and precipitation regimes due to climate change (Toledo-Aceves et al., 2011; Ponce-Reyes et al., 2012). In Mexico, around 90\% of Magnolia species are vulnerable to extinction by habitat loss and fragmentation, and these include M. pedrazae and M. schiedeana (Rivers et al., 2016). Genetic diversity estimates showed that San Luis Potosí is the most diverse region for M. pedrazae, and central Veracruz for $M$. schiedeana. However, only few of these studied localities (e.g., CS and MA) are large populations ( $>300$ individuals), while most of them are small $(<100$ individuals, e.g., JH, FO, TU, MM, CP, MA). In fact, we found localities where the species might be locally extinct, such as TLA in Puebla and MI in Veracruz, as we found a single remaining individual. The TMCF of San Luis Potosí and Veracruz are under strong anthropogenic pressures from ongoing land- 
675

676

677

678

679

680

681

682

683

684

685

686

687

688

689

690

691

692

693

694

695

696

697

698

699

700

701

702

703

704

705

706

707

708

709

710

711

712

713

714

conversion to agriculture and livestock farming (CONABIO, 2010). Moreover, several populations do not occur under Protected Natural Areas, such as the most genetically diverse populations in Veracruz. Protecting and restoring TMCF habitat is crucial for the conservation of Magnolia species (Rivers et al., 2016). This can be accomplished through implementing community-based management strategies, such as the promotion of sustainable and environmentally friendly tourism that can benefit the local communities. There are already successful examples of community-based programs in large remnant TMCF fragments of San Luis Potosí (La Trinidad) and Oaxaca (La Esperanza) that have large Magnolia populations (e.g., FO, CS, SI, SC), and where local communities host ecotourist destinations and agreed the protection of their well-conserved forests forbidding commercial wood extraction.

On the other hand, our niche species distributions suggest that magnolias are sensitive to climatic events since historical times, which lead to range shifts, expansions, and contractions. Future climatic scenarios suggest a decrease of M. schiedeana suitable habitat by 2080 (Vázquez-Morales et al., 2014). Conserving genetic diversity of ancestral populations would be important for the species conservation as ancestral populations are sources of evolutionary adaptive potential (Frankham, 2005). According to our results, we suggest that special attention should be paid to populations in central Veracruz, as these are likely the most ancestral populations and where M. schiedeana is abundant in some localities; the same applies for the northern periphery in San Luis Potosí. Monitoring genetic diversity and evaluating the role of geographical and environmental factors on genetic diversity and gene flow would also be key for the in-situ species management in the long-term.

\section{Acknowledgments}

We thank Bruno A. Gutiérrez Becerril, Sergio Nicasio Arzeta, and Benjamín Castillo Ponce for their assistance in collecting leaf material. We also thank the useful comments from three anonymous reviewers that improved the quality of our work during the revision stage.

\section{References}

Aiello-Lammens ME, Boria RA, Radosavljevic A, Vilela B, Anderson RP. 2015. spThin: an R package for spatial thinning of species occurrence records for use in ecological niche models. Ecography 38:541-545.

Alcántara O, Luna I, Velázquez A. 2002. Altitudinal distribution patterns of Mexican cloud forests based upon preferential characteristic genera. Plant Ecology 161: 167-174.

Aldaba-Núñez FB, Veltjen E, Martínez-Salas EM, Samain MS. 2021. Plants 10: 573

Azuma H, Chalermglin P, Nooteboom HP. 2011. Molecular phylogeny of Magnoliaceae based on plastid DNA sequences with special emphasis on some species from continental Southeast Asia. Botany 39:148-165.

Bertorelle G, Benazzo A, Mona S. 2010. ABC as a flexible framework to estimate demography 
715

716

717

718

719

720

721

722

723

724

725

726

727

728

729

730

731

732

733

734

735

736

737

738

739

740

741

742

743

744

745

746

747

748

749

750

751

752

753

754

over space and time: some cons, many pros. Molecular Ecology 19: 2609-2625.

Cobos ME, Peterson AT, Barve N, Osorio-Olvera L. 2019. kuenm: an R package for detailed development of ecological niche models using Maxent. PeerJ 7:e6281.

CONABIO. 2010. El Bosque Mesófilo de Montaña en México: Amenazas y Oportunidades para su Conservación y Manejo Sostenible. Comisión Nacional para el Conocimiento y Uso de la Biodiversidad, México. 197 p.

Corander J, Sirén J, Arjas E. 2008. Bayesian spatial modeling of genetic population structure. Computational Statistics. 23:111-129.

Cornuet JM, Santos F, Beaumont MA, Robert CP, Marin JM, Balding DJ, Guillemaud T, Estoup A. 2008. Inferring population history with DIY ABC: a user-friendly approach to approximate Bayesian computation. Bioinformatics.24:2713-9.

Cornuet JM, Pudlo P, Veyssier J, Dehne-Garcia A, Gautier M, Leblois R, Marin JM, Estoup A. 2014. DIYABC v2.0: a software to make approximate Bayesian computation inferences about population history using single nucleotide polymorphisms, DNA sequence and microsatellite data. Bioinformatics 30: 1187-1189.

Cruz-Cárdenas G, Villaseñor JL, López-Mata L, Ortiz, E. 2012. Potential distribution of humid mountain forest in Mexico. Botanical Sciences 90: 331-340.

Cruz-Durán R, Vega-Flores K, Jiménez-Ramírez J. 2008. Magnolia vazquezii Magnoliaceae, una especie nueva del estado de Guerrero, Mexico. Novon: A Journal for Botanical Nomenclature 18:21-24.

D'Amen, M., Zimmermann, N. E., Pearman, P. B. 2013. Conservation of phylogeographic lineages under climate change. Global Ecology and Biogeography, 22:93-104.

Dalmaris E, Ramalho CE, Poot P, Veneklaas EJ, Byrne M. 2015. A climate change context for the decline of a foundation tree species in south-western Australia: insights from phylogeography and species distribution modeling. Annals of Botany 116: 941-952.

Darriba D, Taboada GL, Doallo R, Posada D. 2012. jModelTest 2: more models, new heuristics and parallel computing. Nature Methods 9:772.

De Queiroz K. 2007. Species concepts and species delimitation. Systematic Biology 56: 879-886.

Di Febbraro M. Carotenuto F, Castiglione S, Russo D, Loy A, Maiorano L, Raia P. 2017. Does the jack of all trades fare best? Survival and niche width in Late Pleistocene megafauna. Journal of Biogeography 44:2828-2838.

Dieringer G, Espinosa SJE. 1994. Reproductive ecology of Magnolia schiedeana Magnoliaceae a threatened cloud forest tree species in Veracruz, Mexico. Bulletin of the Torrey Botanical Club 121:154-159.

Dong S, Wang Y, Xia N, Liu Y, Liu M, Lian L, Li N, Li L, Lang X, Gong Y, Chen L, Wu E, Zhang S. 2021. Plastid and nuclear phyligenomic incrongruences and biogeographic implications of Magnolia s.1. (Magnoliaceae). Journal of Systematics and Evolution. doi: $10.111 /$ jse. 12727.

Dormann CF, Elith J, Bacher S, Buchmann C, Carl G, Carré G, García-Marquez JR, Gruber B, Lafourcade B, Leitao PJ, Munkemuller T, McClean C, Osborne PE, Reineking B, 
755

756

757

758

759

760

761

762

763

764

765

766

767

768

769

770

771

772

773

774

775

776

777

778

779

780

781

782

783

784

785

786

787

788

789

790

791

792

793

Schroder B, Skidmore AK, Zurell D, Lautenbach S. 2012. Collinearity: a review of methods to deal with it and a simulation study evaluating their performance. Ecography 36: 27-46.

Doyle JJ, Doyle JL. 1987. A rapid DNA isolation procedure for small quantities of fresh leaf tissue. Phytochemical Bulletin 19:11-15.

Drummond AJ, Bouckaert RR. 2015. Bayesian evolutionary analysis with BEAST2 Cambridge University Press, Cambridge, UK.

Edgar RC. 2004. MUSCLE: multiple sequence alignment with high accuracy and high throughput. Nucleic Acids Research 32:1792-1797.

Excoffier L, Fol M, Petit RJ. 2009. Genetic consequences of range expansions. Annual Review of Ecology, Evolution, and Systematics 40:481-501.

Excoffier L, Lischer H. 2010. Arlequin suite ver 3.5: a new series of programs to perform population genetics analyses under Linux and Windows. Molecular Ecology Resources 10:564-567.

Ferrari L, Orozco-Esquivel MT, Manea V, Manea M. 2012. The dynamic history of the TransMexican Volcanic Belt and the Mexico subduction zone. Tectonophysics. 522-523: 122149

Fordham DA, Saltré F, Haythorne S, Wigley TML, Otto-Bliesner BL, Chan KC, Brook BW. 2017. PaleoView: a tool for generating continuous climate projections spanning the last 21000 years at regional and global scales. Ecography 40:1348-1358.

Frankham R. 2005. Genetics and extinction. Biological Conservation, 126: 131-140.

Frigola A, Prange M, Schulz M. 2018. Boundary conditions for the middle Miocene climate transition MMCT v1.0. Geoscientific Model Development 114:1607-1626.

$\mathrm{Fu}$ YX, 1997. Statistical tests of neutrality of mutations against population growth, hitchhiking and background selections. Genetics 174: 918-925.

Galante PJ, Alade B, Muscarella R, Jansa SA, Goodman SM, Anderson RP. 2018. The challenge of modeling niches and distributions for data-poor species: a comprehensive approach to model complexity. Ecography 41:726-736

González-Espinosa M, Meave JA, Lorea-Hernández FG, Ibarra-Manriquez G, Newton AC. 2011. The red list of Mexican Cloud Forest trees. Fauna and Flora International, Cambridge

Graham A. 1999. Studies in Neotropical paleobotany. XIII. An Oligo-Miocene palynoflora from Simojovel Chiapas, Mexico. American Journal of Botany 86:17-31.

Gual-Díaz M, González-Medrano F. 2014. Los bosques mesófilos de montaña de México. GualDíaz, M. \& A. Rendón-Correa (eds) In: Bosques Mesófilos de Montaña de México: diversidad, ecología y manejo. Comisión Nacional para el Conocimiento y Uso de la Biodiversidad. México, DF, México, 189-196.

Guevara L, Morrone JJ, León-Paniagua L. 2018. Spatial variability in species' potential distributions during the Last Glacial Maximum under different Global Circulation 
794

795

796

797

798

799

800

801

802

803

804

805

806

807

808

809

810

811

812

813

814

815

816

817

818

819

820

821

822

823

824

825

826

827

828

829

830

831

832

833

Models: relevance in evolutionary biology. Journal of Zoological Systematics and Evolutionary Research 57:113-126.

Guevara L. 2020. Altitudinal, latitudinal and longitudinal responses of cloud forest species to Quaternary glaciations in the northern Neotropics. Biological Journal of the Linnean Society. 130: 615-625.

Gutiérrez-Rodríguez C, Ornelas JF, Rodríguez-Gómez F. 2011. Chloroplast DNA phylogeography of a distylous shrub Palicourea padifolia, Rubiaceae reveals past fragmentation and demographic expansion in Mexican cloud forests. Molecular Phylogenetics and Evolution 61: 603-615.

Harpending H, Batzer M, Gurven M, Jorde L, Rogers A, Sherry S. 1998. Genetic traces of ancient demography. Proceedings of the National Academy of Sciences of the United States of America. 95:1961-1967.

Hebda RJ, Irving E. 2004. On the origin and distribution of magnolias: tectonics, DNA and climate change. In: Channell JET, Kent DV, Lowrie W, Meert JG (eds) Timescales of the paleomagnetic field. Greophysical monograph series 145. American Geophysical Union, Washington DC, pp 43-57.

Hijmans RJ. 2020. raster: geographic data analysis and modeling. R package version 3.3-13. https://CRAN.R-project.org/package=raster

Huang JP. 2020. Is population subdivision different from speciation? From phylogeography to species delimitation. Ecology and Evolution 10:6890-6896.

Huelsenbeck JP, Ronquist F. 2001. MrBayes: Bayesian inference of phylogenetic trees. Bioinformatics 17:754-755

Jiménez-Ramírez J, Vega-Flores K, Cruz-Durán R, Vázquez-García JA. 2007. Una nueva especie del bosque mesófilo de montaña del estado de Guerrero, México. Botanical Sciences 80:73-76

Karger DN, Conrad O, Böhner J, Kawohl T, Kreft H, Soria-Auza RW, Zimmermann NE, Linder HP, Kessler M. 2017. Climatologies at high resolution for the earth's land surface areas. Scientific Data 4:170122.

Karger DN, Conrad O, Böhner J, Kawohl T, Kreft H, Soria-Auza RW, Zimmermann NE, Linder HP, Kessler M. 2018. Data from: Climatologies at high resolution for the earth's land surface areas. Dryad Digital Repository. http://dx.doi.org/doi:10.5061/dryad.kd1d4

Kikuchi S, Osone Y. 2021. Subspecies divergence and pronounced phylogenetic incongruence in the East-Asia-endemic shrub Magnolia sieboldii. Annals of Botany 127: 75-90

Kumar S, Stecher G, Li M, Knyaz C, Tamura K. 2018. MEGA X: molecular evolutionary genetics analysis across computing platforms. Molecular Biology and Evolution. 35:1547-9.

Leigh JW, Bryant D. 2015. Popart: full-feature software for haplotype network construction. Methods in Ecology and Evolution 6:1110-1116.

Manolopoulou I, Emerson BC. 2012. Phylogeographic ancestral inference using the coalescent model on haplotype trees. Journal of Computational Biology. 19:745-55. 
834

835

836

837

838

839

840

841

842

843

844

845

846

847

848

849

850

851

852

853

854

855

856

857

858

859

860

861

862

863

864

865

866

867

868

869

870

871

872

Manolopoulou I, Hille A, Emerson BC. 2020. BPEC: An R package for Bayesian phylogeographic and ecological clustering. Journal of Statistical Software 92: 1-32

Manolopoulou I, Legarreta L, Emerson BC, Brooks S, Tavaré S. 2011. A Bayesian approach to phylogeographic clustering. Interface focus 1: 909-921.

Mastretta-Yanes A, Moreno-Letelier A, Piñero D, Jorgensen TH, Emerson BC. 2015. Biodiversity in the Mexican highlands and the interaction of geology, geography and climate within the Trans-Mexican Volcanic Belt. Journal of Biogeography 42:15861600.

Mesgaran MB, Cousens RD, Webber BL. 2014. Here be dragons: a tool for quantifying novelty due to covariate range and correlation change when projecting species distribution models. Diversity and Distributions 20: 1147-1159.

Muscarella R, Galante PJ, Soley-Guardia M, Boria RA, Kass JM, Uriarte M, Anderson RP. 2014. ENMeval: an R package for conducting spatially independent evaluations and estimating optimal model complexity for Maxent ecological niche models. Methods in Ecology and Evolution 5:1198-1205.

Nakazato T, Warren DL, Moyle LC. 2010. Ecological and geographic modes of species divergence in wild tomatoes. American Journal of Botany 97:680-693.

Newton AC, Robertson A, Williams-Linera G, Rámirez-Marcial N, González-Espinosa M, Allnutt TR, Ennos R 2007 Genetic variation in two rare endemic mexican trees, Magnolia sharpii and Magnolia schiedeana. Silvae Genetica 57:348-356

Oksanen J, Blanchet FG, Kindt R, Legendre P, Minchin PR, O'Hara RB, Simpson GL, Solymos P, Stevens MH, Wagner H. 2015. Vegan: Community ecology package. Ordination methods, diversity analysis and other functions for community and vegetation ecologist. $\mathrm{R}$ package version. 2015:2-3

Ornelas JF, Ortiz-Rodriguez AE, Ruiz-Sanchez E, Sosa V, Pérez-Farrera MA. 2019. Ups and downs: genetic differentiation among populations of the Podocarpus Podocarpaceae species in Mesoamerica. Molecular Phylogenetics and Evolution 138:17-30.

Ornelas JF, Sosa V, Soltis DE, Daza JM, González C, Soltis PS, Gutiérrez-Rodríguez C, Espinoza de los Monteros AE, Castoe TA, Bell C, Ruiz-Sanchez E. 2013. Comparative phylogeographic analyses illustrate the complex evolutionary history of threatened cloud forests of northern Mesoamerica. PloS One 8: e56283.

Osorio-Olvera L, Lira-Noriega A, Soberón J, Peterson AT, Falconi M, Contreras-Díaz RG, Martínez-Meyer E, Barve V, Barve N. 2020. NTBOX: An r package with graphical user interface for modeling and evaluating multidimensional ecological niches. Methods in Ecology and Evolution 11:1199-206

Otto-Bliesner BL. 2006. Simulating arctic climate warmth and icefield retreat in the last interglaciation. Science 311:1751-1753.

Paradis E. 2010. pegas: an R package for population genetics with an integrated-modular approach. Bioinformatics 26:419-420. 
873

874

875

876

877

878

879

880

881

882

883

884

885

886

887

888

889

890

891

892

893

894

895

896

897

898

899

900

901

902

903

904

905

906

907

908

909

910

911

912

Phillips SJ, Anderson RP, Dudík M, Schapire RE, Blair ME. 2017. Opening the black box: an open-source release of Maxent. Ecography 40:887-893.

Pineda E, Moreno C, Escobar F, Halffter G. 2005. Frog, bat, and dung beetle diversity in the cloud forest and coffee agroecosystems of Veracruz, Mexico. Conservation Biology 19:400-410.

Ponce-Reyes R, Reynoso-Rosales VH, Watson JE, VanDerWal J, Fuller RA, Pressey RL, Possingham HP. 2012. Vulnerability of cloud forest reserves in Mexico to climate change. Nature Climate Change 2:448-452.

Pons O, Petit RJ. 1996. Measuring and testing genetic differentiation with ordered versus unordered alleles. Genetics 144:1237-1245.

Prance G. 1982. A Review of the phytogeographic evidences for Pleistocene climate changes in the neotropics. Annals of the Missouri Botanical Garden 69:594-624.

R Core Team. (2020). R: A Language and Environment for Statistical Computing. Vienna, Austria. Retrieved from https://www.R-project.org/

Rahbek C, Borregaard MK, Antonelli A, Colwell RK, Holt BG, Nogues-Bravo D, Rasmussen CM, Richardson K, Rosing MT, Whittaker RJ Fjeldså J. 2019. Building mountain biodiversity: Geological and evolutionary processes. Science 365:1114-1119.

Rambaut A, Drummond AJ, Xie D, Baele G, Suchard MA. 2018. Posterior summarisation in Bayesian phylogenetics using Tracer 1.7. Systematic Biology. 67:901.

Ramírez-Barahona S, Eguiarte LE. 2013. The role of glacial cycles in promoting genetic diversity in the Neotropics: the case of cloud forests during the Last Glacial Maximum. Ecology and Evolution 3:725-738.

Ramírez-Barahona S, Sauquet H, Magallón S. 2020. The delayed and geographically heterogenous diversification of flowering plant families. Nature Ecology and Evolution 4: 1232-1238

Ramos-Onsins SE, Rozas J. 2002. Statistical properties of new neutrality tests against population growth. Molecular Biology and Evolution 19: 2092-2100.

Randin CF, Engler R, Normand S, Zappa M, Zimmermann NE, Pearman PB, Vittoz P, Thuiller W, Guisan A. 2009. Climate change and plant distribution: local models predict highelevation persistence. Golbal Chance Biology 15:1557-1569.

Richardson AO, Rice DW, Young GJ, Alverson AJ, Palmer JD. 2013. The "fossilized" mitochondrial genome of Liriodendron tulipifera: ancestral gene content and order, ancestral editing sites, and extraordinarily low mutation rate. BMC Biology 11:1-17.

Rico Y, Becerril BAG. 2019. Species delimitation and genetic structure of two endemic Magnolia species (section Magnolia; Magnoliaceae) in Mexico. Genetica, 147: 57-68.

Rivers MC, Beech E, Murphy L, Oldfield SF. 2016. The Red List of Magnoliaceae-revised and extended. BGCI, Richmond UK. ISBN: 1-905164-64-5

Rodríguez-Ramírez EC, Valdez-Nieto JA, Vázquez-García JA, Dieringer G, Luna-Vega I. 2020. Plastic Responses of Magnolia schiedeana Schltdl., a Relict-Endangered Mexican Cloud Forest Tree, to Climatic Events: Evidences from Leaf Venation and Wood Vessel Anatomy. 
913

914

915

916

917

918

919

920

921

922

923

924

925

926

927

928

929

930

931

932

933

934

935

936

937

938

939

940

941

942

943

944

945

946

947

948

949

950

\section{Forests 11:737}

Rozas J, Ferrer-Mata A, Sánchez-DelBarrio JC, Guirao-Rico S, Librado P, Ramos-Onsins SE, Sánchez-Gracia A. 2017. DnaSP 6: DNA Sequence Polymorphism Analysis of Large Datasets. Molecular Biology and Evolution 34:3299-3302.

Ruiz-Sánchez E, Ornelas JF. 2014. Phylogeography of Liquidambar styraciflua A ltingiaceae in Mesoamerica: survivors of a Neogene widespread temperate forest or cloud forest in North America?. Ecology and Evolution 4:311-328.

Rzedowski J. 1978. Vegetación de México. Ed. Limusa, Mexico, DF.

Rzedowski J. 1996. Análisis preliminar de la flora vascular de los bosques mesófilos de montaña de México. Acta Botanica Mexicana 35:25-44.

Salces-Castellano A, Stankowski S, Arribas P, Patiño J, Karger DN, Butlin R, Emerson BC. 2021. Long-term cloud forest response to climate warming revealed by insect speciation history. Evolution 75: 231-244.

Sánchez-González LA, Morrone JJ, Navarro-Sigüenza AG. 2008. Distributional patterns of the Neotropical humid montane forest avifaunas. Biological Journal of the Linnean Society 94:175-194.

Scoble J, Lowe AJ. 2010. A case for incorporating phylogeography and landscape genetics into species distribution modeling approaches to improve climate adaptation and conservation planning. Diversity and Distributions 16:343-353.

SEMARNAT Secretaría de Medio Ambiente y Recursos Naturales. 2010. NOM-059SEMARNAT-2010 de protección ambiental - especies nativas de México de flora y fauna silvestres - categorías de riesgo, especificaciones para su inclusión, exclusión o cambio lista de especies en riesgo. Diario Oficial de la Federación. 30 de Diciembre del 2010. Segunda sección, México.

Setsuko S, Tomaru N. 2009. Estimation of outcrossing rates at hierarchical levels of fruits, individuals, populations and species in Magnolia stellata. Heredity 102:381-8

Shaw J, Lickey EB, Beck JT, Farmer SB, Liu W, Miller J, Siripun KC, Winder CT, Schilling EE, Small RL. 2005. The tortoise and the hare II: relative utility of 21 noncoding chloroplast DNA sequences for phylogenetic analysis. American Journal of Botany 92:142-166.

Tajima F. 1989. Statistical-method for testing the neutral mutation hypothesis by DNA polymorphism. Genetics 123:585-595.

Tobe JD, Abbott AG, Ballard R. 1993. Inheritance of chloroplast DNA in Magnolia. Magnolia, 54:25-31.

Toledo VM. 1982. Pleistocene changes of vegetation in tropical Mexico. In G. T. Prance editor, Biological Diversification in the Tropics. Columbia Univ. Press, New York.

Toledo-Aceves T, Meave JA, González-Espinoza M, Ramírez-Marcial N. 2011. Tropical montane cloud forest: Current threats and opportunities for the conservation and sustainable management in Mexico. Journal of Environmental Management 92:974-981.

Peer) reviewing PDF | (2020:12:56057:3:0:NEW 1 Aug 2021) 
951

952

953

954

955

956

957

958

959

960

961

962

963

964

965

966

967

968

969

970

971

972

973

974

975

976

977

978

979

980

981

982

983

984

985

986

987

988

989

990

Twyford AD, Kidner CA, Harrison N, Ennos RA. 2012. Population history and seed dispersal in widespread Central American Begonia species Begoniaceae inferred from plastomederived microsatellite markers. Botanical Journal of the Linnean Society. 171:260-76.

Vaidya G, Lohman DJ, Meier R. 2011. SequenceMatrix: concatenation software for the fast assembly of multi-gene datasets with character set and codon information. Cladistics 27:171-180.

Vásquez-Morales SG, Sánchez-Velásquez LR, del Rosario Pineda-López M, Díaz-Fleischer F, Flores-Estévez N, Viveros-Viveros H. 2017. Moderate anthropogenic disturbance does not affect the demography of Magnolia schiedeana, an endangered species from Mexico. Flora 234:77-83.

Vásquez-Morales SG, Sánchez-Velásquez LR. 2011. Seed ecology and pre-germinative treatments in Magnolia schiedeana Schlecht, an endangered species from Mexico. Journal of Food, Ecology and Agriculture 9: 604-608.

Vásquez-Morales SG, Téllez-Valdés O, del Rosario Pineda-López M, Sánchez-Velásquez LR, Flores-Estevez N, Viveros-Viveros H. 2014. Effect of climate change on the distribution of Magnolia schiedeana: a threatened species. Botanical Sciences 92:575-585.

Vázquez-García JA, Muñiz-Castro MA, Arroyo F, Pérez AI, Serna M, Cuevas-Guzmán R, Domínguez-Yescas R, de Castro-Arce E, Gurrola-Diaz CM 2013 Novelties of the neotropical Magnolia and addendum proposal the IUCN red list of Magnoliaceae. In: Salcedo-Pérez E, Hernández-Álvarez E, Vázquez-García JA, Escoto-García T, DíazEchavarría N eds Recursos Forestales en el Occidente de Mexico, Diversidad, Manejo, Aprovechamiento y Conservación. Universidad de Guadalajara. ISBN978-607-8072-73-6

Vázquez-García JA, Muñiz-Castro MA, De Castro-Arce E, Murguía R, Nuño A, CházaroBasáñez M. 2012. Twenty new Neotropical tree species of Magnolia. Recursos forestales en el occidente de México 4:91-130.

Vázquez-García JA, Pérez-Farrera MÁ, Gómez-Domínguez H, Muñiz-Castro MA, SagahúnDomínguez E. 2017 Magnolia montebelloensis, a new species in section Magnolia from Lagunas de Montebello National Park, Chiapas, México, with a key to Magnoliaceae of Chiapas. Phytotaxa 328:101-114.

Vázquez-García JA. 1994. Magnolia Magnoliaceae in Mexico and Central America: a synopsis. Brittonia 46:1-23.

Venkatraman, MX, Deraad DA, Tsai WLE, Zarza E, Zellmer AJ, Maley JM, McCormack JE. 2019. Cloudy with a chance of speciation: Integrative taxonomy reveals extraordinary divergence within a Mesoamerican cloud forest bird. Biological Journal of the Linnean Society 126:1-15.

Vite A. 2016. Estructura poblacional de Magnolia schiedeana Schltdl. en dos ambientes contrastantes en el estado de Hidalgo, México Tesis de maestría. Universidad Autónoma del Estado de Hidalgo, Pachuca, México.

Wang YB, Liu BB, Nie ZL, Chen HF, Chen FJ, Figlar RB, Wen J. 2020. Major clades and a revised classification of Magnolia and Magnoliaceae based on whole plastid genome 
991 sequences via genome skimming. Journal of Systematics and Evolution 58:673- 695.

992 Warren DL, Glor RE, Turelli M. 2008. Environmental niche equivalency versus conservatism:

993 quantitative approaches to niche evolution. Evolution 62:2868-2883.

994 Watanabe K, Ikegami F, Horie S. 2002. Introduction the genus Magnolia. In: Satyajit, S.D., Yuji, 995 M. Eds., Magnolia: The genus Magnolia. Taylor and Francis, New York, USA, pp. 1-7. 996 Wolfe KH, Li WH, Sharp PM. 1987. Rates of nucleotide substitution vary greatly among plant 997 mitochondrial, chloroplast, and nuclear DNAs. Proceedings of the National Academy of 998 Sciences of the United States of America 84:9054-9058.

999

1000 


\section{Table $\mathbf{1}$ (on next page)}

Sampling locations, population code, state, species, sample size (n), haplotypes, nucleotide, and haplotype diversity of $M$. pedrazae, $M$. schiedeana and $M$. schiedeana pop. Oaxaca.

Haplotypes denoted in bold are private haplotypes to the population. State abbreviations as follows: SLP San Luis Potosí, QRO Querétaro, HGO Hidalgo, PUE Puebla, VER Veracruz, OAX Oaxaca 


\begin{tabular}{|c|c|c|c|c|c|c|c|}
\hline Location & Code & State & Species & $\mathbf{n}$ & Haplotypes (no. of individuals) & $\begin{array}{l}\text { Nucleotide } \\
\text { diversity }(\pi)\end{array}$ & $\begin{array}{l}\text { haplotype } \\
\text { diversity (Hd) }\end{array}$ \\
\hline Las Flores & FO & SLP & M. pedrazae & 3 & H18(1), H20(1), H21(1) & 0.00047 & $1 \pm 0.27$ \\
\hline La Silleta & SI & SLP & M. pedrazae & 4 & H31(2), H46(1), H47(1) & 0.00093 & $0.83 \pm 0.2$ \\
\hline Coronel Castillo & $\mathrm{CS}$ & SLP & M. pedrazae & 4 & H01(1), H02(1), H18(1), H19(1) & 0.00169 & $1 \pm 0.18$ \\
\hline $\begin{array}{l}\text { Joya del Hielo \& } \\
\text { Yesca }\end{array}$ & $\mathrm{JH}$ & QRO & M. pedrazae & 6 & $\begin{array}{l}\mathrm{H} 18(1), \mathrm{H} 20(1), \mathbf{H 2 9}(1), \mathbf{H 3 0}(1), \mathrm{H} 31(1), \\
\text { H32(1) }\end{array}$ & 0.00075 & $1 \pm 0.09$ \\
\hline Tlanchinol & $\mathrm{TL}$ & $\mathrm{HGO}$ & M. schiedeana & 5 & H02(2), H12(1), H35(1), H48(1) & 0.00105 & $0.9 \pm 0.16$ \\
\hline La Mojonera & MO & HGO & M. schiedeana & 7 & H03(2), H25(1), H26(1), H35(2), H38(1) & 0.00067 & $0.9 \pm 0.1$ \\
\hline El Hayal & HA & $\mathrm{HGO}$ & M. schiedeana & 6 & H03(3), H26(1), H27(1), H28(1) & 0.00077 & $0.8 \pm 0.17$ \\
\hline Tutotepec & TU & $\mathrm{HGO}$ & M. schiedeana & 6 & H03(4), H12(1), H49(1) & 0.00023 & $0.6 \pm 0.2$ \\
\hline Medio Monte & MM & $\mathrm{HGO}$ & M. schiedeana & 6 & $\begin{array}{l}\text { H02(1), H03(1), H15(1), H25(1), H35(1), } \\
\text { H37(1) }\end{array}$ & 0.0007 & $1 \pm 0.09$ \\
\hline El Gosco & GO & HGO & M. schiedeana & 6 & H02(2), H03(1), H15(1), H24(1), H25(1) & 0.00068 & $0.93 \pm 0.12$ \\
\hline El Cirio & CI & HGO & M. schiedeana & 6 & H03(2), H11(2), H12(1), H13(1) & 0.001 & $0.87 \pm 0.13$ \\
\hline Tlatlauquitepec & TLA & PUE & M. schiedeana & 1 & H10(1) & - & - \\
\hline Misantla & MI & VER & M. schiedeana & 1 & H36(1) & - & - \\
\hline Volcán de Acatlán & $\mathrm{AC}$ & VER & M. schiedeana & 9 & $\begin{array}{l}\mathrm{H} 01(1), \mathrm{H} 02(1), \mathrm{H} 03(1), \mathbf{H 0 4}(1), \mathbf{H 0 5}(1), \\
\text { H06(1), H07(1), H08(1), H09(1) }\end{array}$ & 0.00134 & $1 \pm 0.05$ \\
\hline La Martinica & MA & VER & M. schiedeana & 5 & H03(1), H12(1), H33(1), H34(1), H35(1) & 0.00133 & $1 \pm 0.13$ \\
\hline Mesa de la Yerba & MY & VER & M. schiedeana & 5 & H03(1), H39(1), H40(1), H41(1), H42(1) & 0.00154 & $1 \pm 0.13$ \\
\hline Cinco Palos & $\mathrm{CP}$ & VER & M. schiedeana & 4 & H14(1), H15(1), H16(1), H17(1) & 0.00128 & $1 \pm 0.18$ \\
\hline Reserva Ecológica & FXC & VER & M. schiedeana & 2 & $\mathbf{H} 22(1), \mathbf{H} 23(1)$ & 0.00035 & $1 \pm 0.5$ \\
\hline El Zapotal & $\mathrm{ZA}$ & VER & M. schiedeana & 5 & H02(1), H03(2), H12(1), H35(1) & 0.00042 & $0.9 \pm 0.16$ \\
\hline $\begin{array}{l}\text { Santiago } \\
\text { Comaltepec }\end{array}$ & $\mathrm{SC}$ & OAX & $\begin{array}{l}\text { M. schiedeana } \\
\text { pop Oaxaca }\end{array}$ & 5 & H43(3), H44(1), H45(1) & 0.0007 & $0.7 \pm 0.22$ \\
\hline
\end{tabular}

1 


\section{Table 2 (on next page)}

AMOVA results of distinct hierarchical groups for 20 populations of $M$. pedrazae, $M$. schiedeana, and M. schiedeana pop. Oaxaca

Analyzed groups: 1) No predefined groups, 2) populations grouped in two lineages $M$.

schiedeana + M. pedrazae and M. schiedeana pop. Oaxaca and 3) populations grouped by the three lineages corresponding $M$. schiedeana, $M$. pedrazae and $M$. schiedeana pop.

Oaxaca. ${ }^{* * P}<0.01 ; * * P<0.001$. 
1

\begin{tabular}{llllll}
\hline Grouping & df & $\begin{array}{l}\text { Sum of } \\
\text { squares }\end{array}$ & $\begin{array}{l}\text { Estimated } \\
\text { variance }\end{array}$ & $\begin{array}{l}\text { Fixation } \\
\text { indices }\end{array}$ \\
\hline 1. No groups defined & & & & & \\
Among populations & 17 & 78.675 & 0.6314 & 32.46 & \\
Within populations & 77 & 101.147 & 1.3136 & 67.54 & $F_{S T}=0.325^{* * *}$ \\
$\begin{array}{l}\text { Total } \\
\text { 2. Two lineages }\end{array}$ & 94 & 179.82 & 1.945 & & \\
Among groups & 1 & 25.126 & 2.3079 & 57.58 & $F_{C T}=0.576^{* * *}$ \\
Among populations & 16 & 53.549 & 0.3864 & 9.64 & $F_{S C}=0.227^{* * *}$ \\
within groups & & & & & \\
Within populations & 77 & 101.147 & 1.3136 & 32.78 & $F_{S T}=0.672^{* * *}$ \\
Total & 94 & 179.823 & 4.008 & & \\
3. Three lineages & & & & & \\
Among groups & 2 & 50.706 & 1.3217 & 48.25 & $F_{C T}=0.483^{* * *}$ \\
Among populations & 15 & 27.97 & 0.1041 & 3.8 & $F_{S C}=0.073^{* *}$ \\
within groups & & & & & \\
Within populations & 77 & 101.147 & 1.3136 & 47.95 & $F_{S T}=0.5205^{* * *}$ \\
Total & 94 & 179.823 & 2.739 & & \\
\hline
\end{tabular}

2

3

4

5 


\section{Table 3 (on next page)}

Genetic diversity, neutrality tests and mismatch distributions for $M$. pedrazae, $M$. schiedeana and M. schiedeana pop. Oaxaca.

$N$ number of individuals, $N_{H}$ number of haplotypes, $\pi$ nucleotide diversity, $H_{d}$ haplotypic diversity, $D_{\mathrm{T}}$ Tajima's $D, F_{\mathrm{S}}$ Fu's Fs, R2 Ramos-Onsins and Rozas, SDD differences in the sum of squares, Hri Harpending's raggedness index. $* P<0.05 ; * * P<0.01$ 
1

\begin{tabular}{|c|c|c|c|c|c|c|c|c|c|}
\hline Lineages & $\mathbf{N}$ & $N_{H}$ & $\pi$ & $\boldsymbol{H}_{d}$ & $D_{\mathrm{T}}$ & $F s$ & $R 2$ & SSD & Hri \\
\hline M. pedrazae & 17 & 12 & 0.00098 & 0.949 & -0.524 & -0.386 & 0.117 & 0.0036 & 0.0258 \\
\hline M. schiedeana & 74 & 36 & 0.001 & 0.923 & $-2.09 *$ & $-4.621 * *$ & $0.0356 * *$ & 0.0009 & 0.0236 \\
\hline $\begin{array}{l}\text { M. schiedeana } \\
\text { pop. Oaxaca }\end{array}$ & 5 & 3 & 0.0007 & 0.7 & -1.12 & -1.124 & 0.253 & 0.0939 & 0.290 \\
\hline
\end{tabular}

2

3

4 
Figure 1

Sampled localities of M. pedrazae, M. schiedeana and M. schiedeana pop. Oaxaca across the TMCF in Mexico.

State abbreviations see in Table 1.

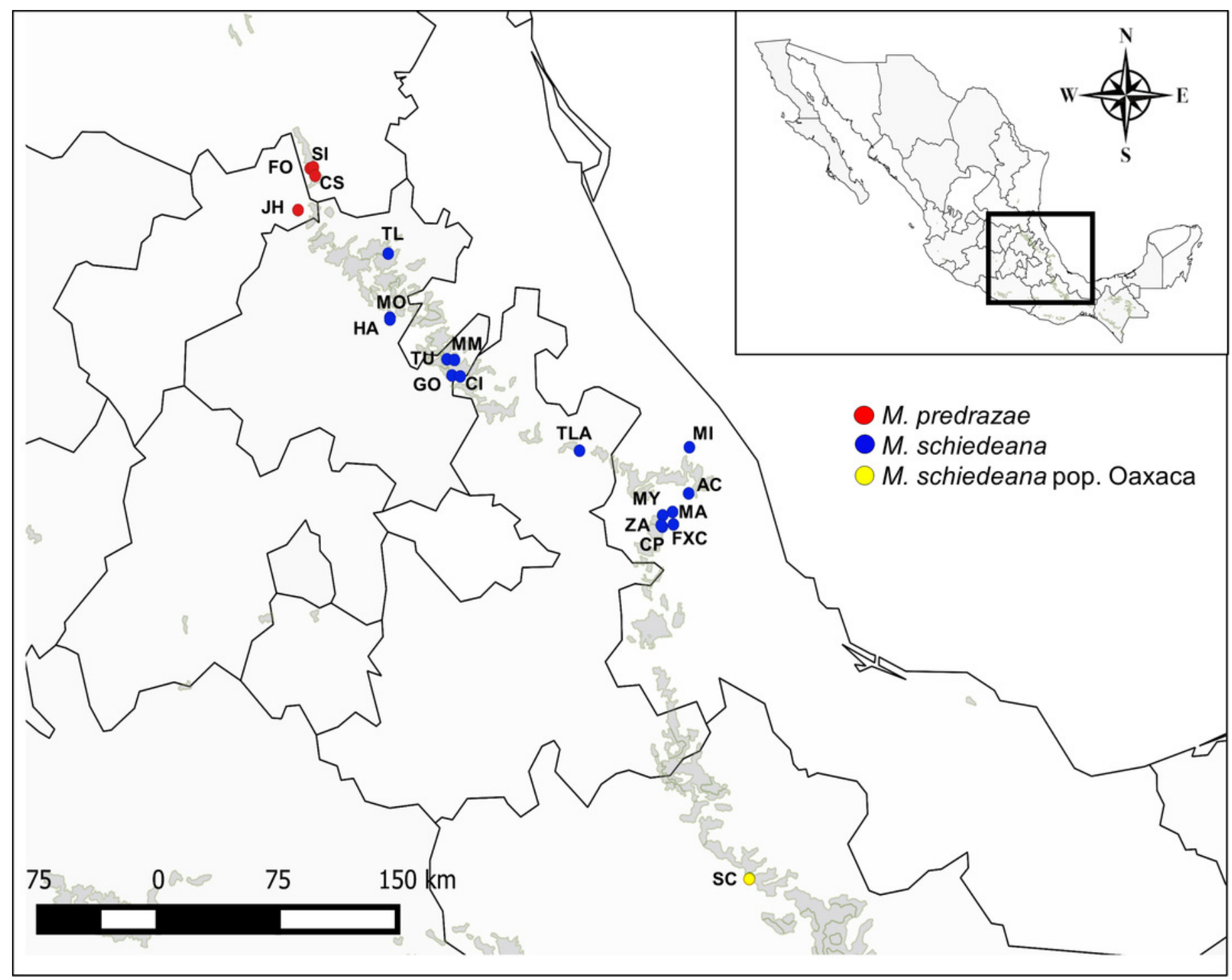




\section{Figure 2}

Phylogenetic and haplotype relationships among $M$. pedrazae, $M$. schiedeana and $M$. schiedeana pop. Oaxaca using four concatenated cpDNA regions.

(A) Bayesian phylogenetic tree, (B) Median-joining haplotype network, (C) BAPS $K=5$ genetic clusters, and (D) BEPC K = 3 genetic clusters and (E-F) PCA plots for eight bioclimatic variables showing the environmental differences for the three clusters. State abbreviations see in Table 1.

A

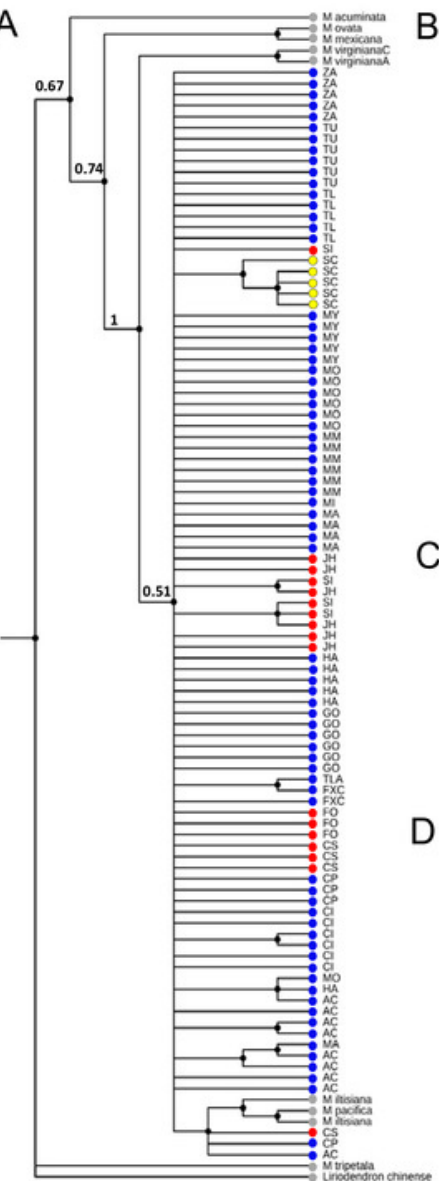

B

C

D
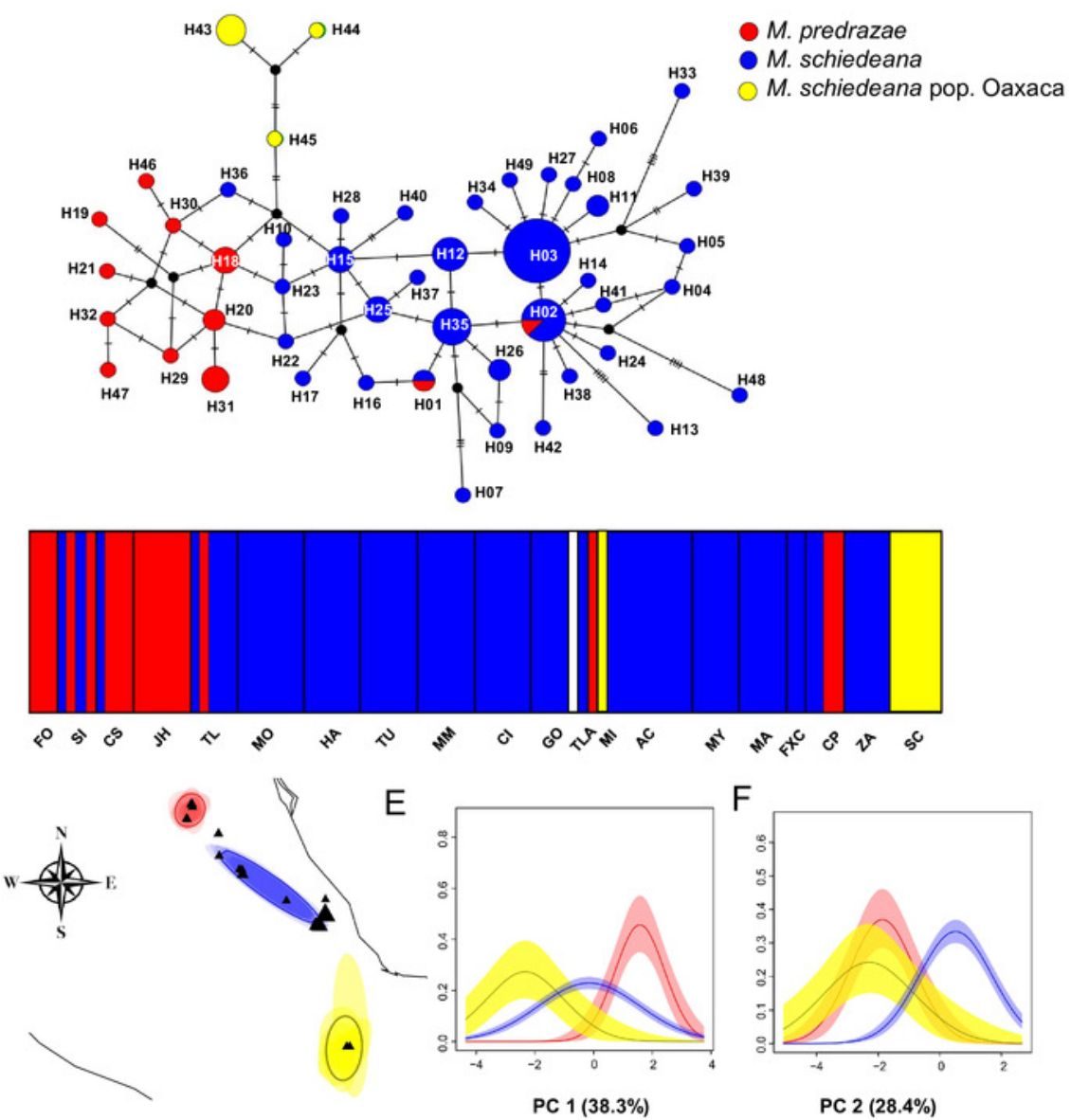
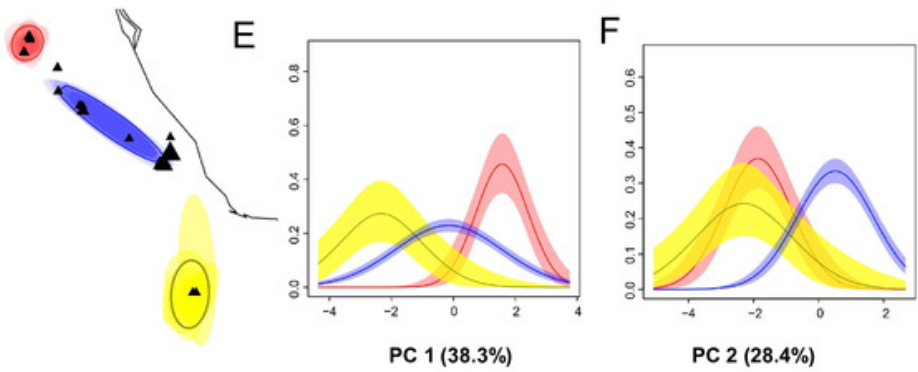


\section{Figure 3}

Historical demographic analysis for M. pedrazae and M. schiedeana.

Mismatch distributions for a sudden expansion model in (A) M. pedrazae and (B) M.

schiedeana. Bayesian skyline plots for (C) M. pedrazae and (D) M. schiedeana. The blue line traces the inferred median effective population size over time with 95\% HPD shaded in blue. The black vertical line is the median projected on the expansion timeline.
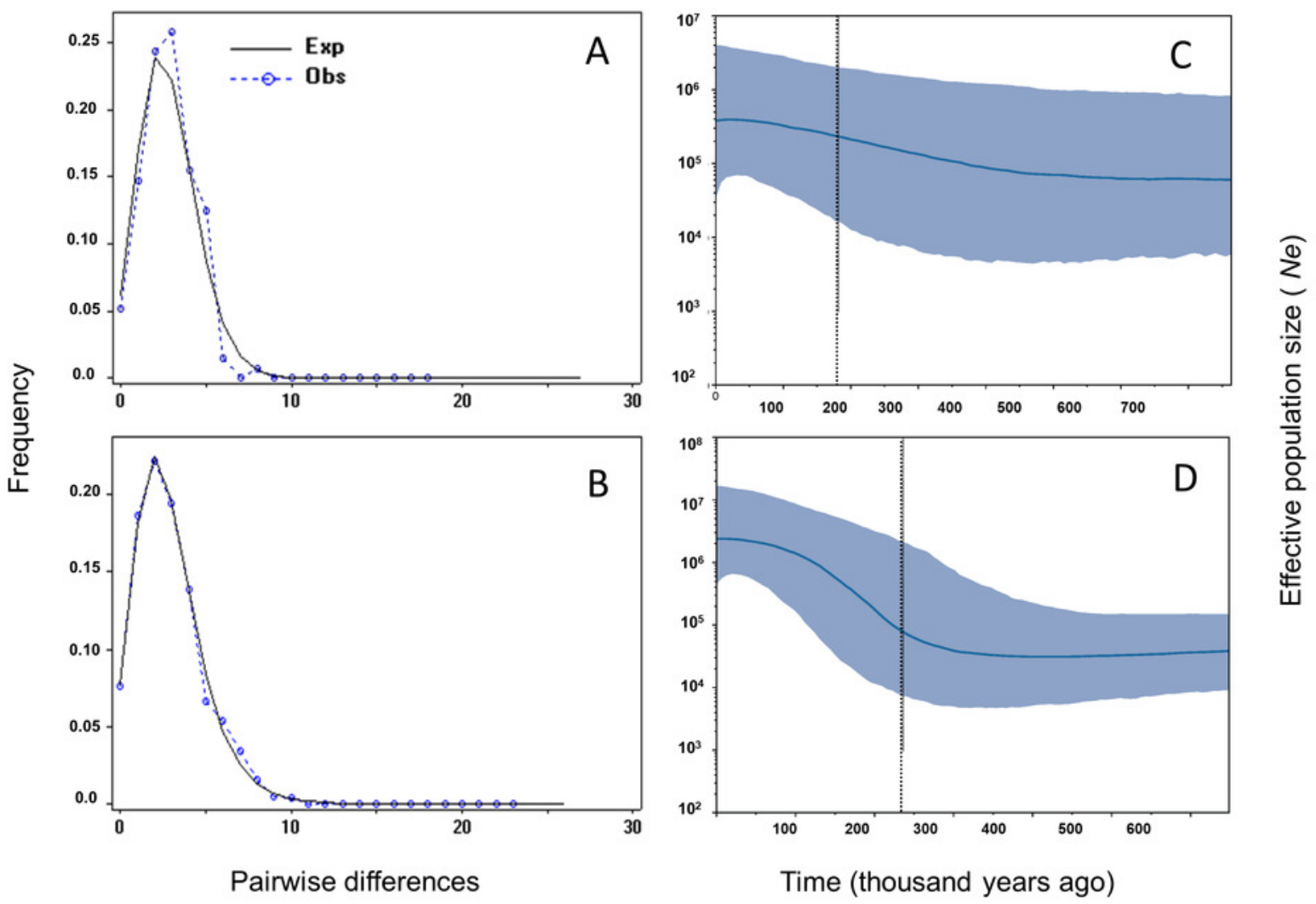


\section{Figure 4}

Approximate Bayesian Computation of five competing demographic scenarios for $M$. pedrazae, M. schiedeana and M. schiedeana pop. Oaxaca simulated in DIYABC

(A) Scenario 1 predicts the three lineages diverging at the same time from a common ancestor (NA) at $t_{2}$ (stable model); (B) Scenario 2 predicts a split between M. schiedeana and M. pedrazae at time $t_{1}$, then both merged with M. schiedeana pop. Oaxaca at time $t_{2} ;(C)$ Scenario 3 predicts a split between $M$. schiedeana pop. Oaxaca and $M$. pedrazae at $t_{1}$ and subsequently both merged with M. schiedeana at $t_{2}$; (D) Scenario 4 predicts a split between M. schiedeana and $M$. schiedeana pop. Oaxaca at $t_{1}$ then both merged with $M$. pedrazae at $t_{2}$. These three scenarios correspond to a divergence model. (E) Scenario 5 predicts secondary contact between the three lineages at time $t_{1}$ (admixture model) 


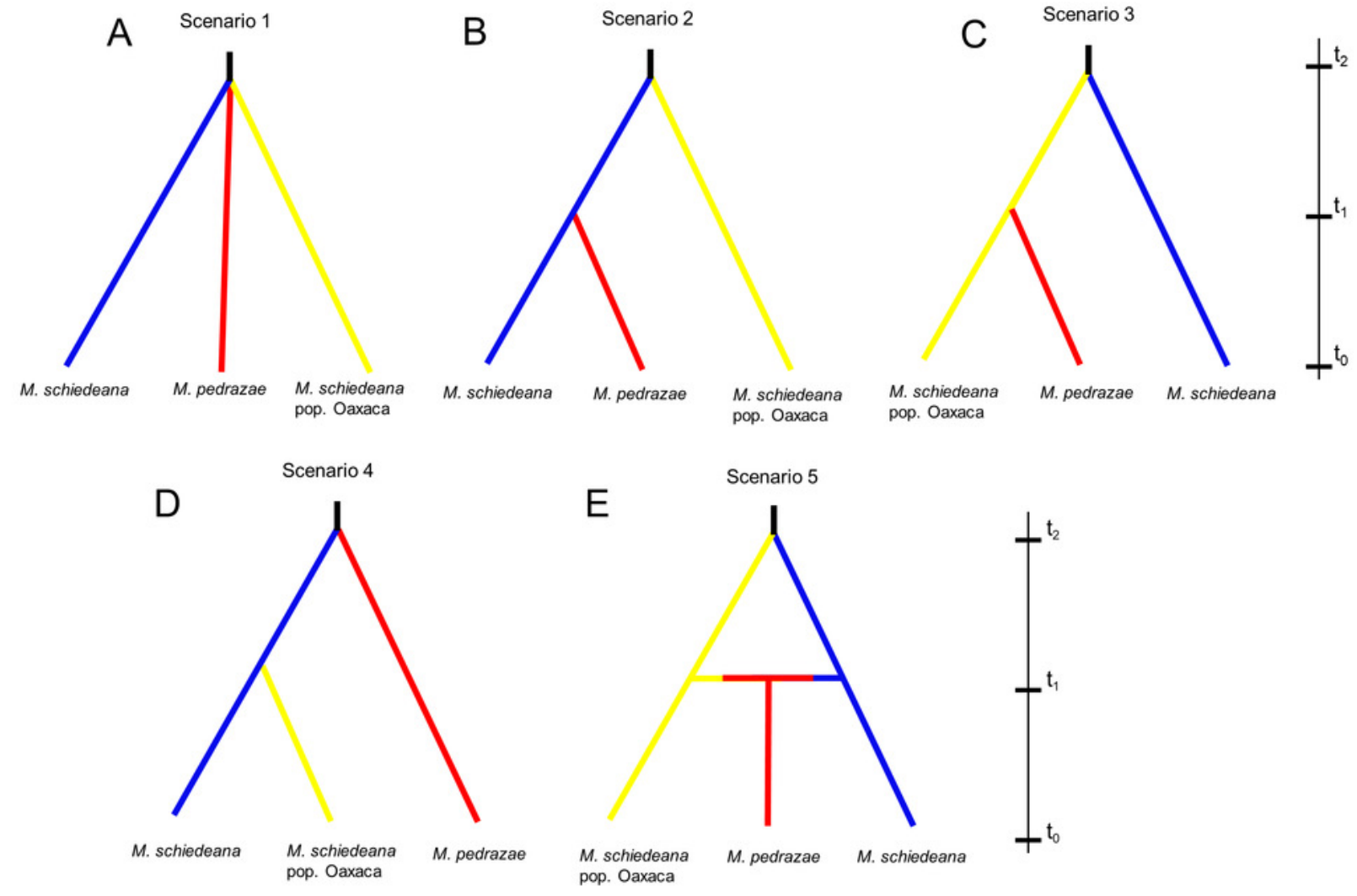


Figure 5

Present and past species distributions modeling for Magnolia pedrazae (red dots), $M$. schiedeana (blue dots) and M. schiedeana pop. Oaxaca (yellow dots).

A) The three lineage occurrences, (B) Present niche model, (C) Mid-Holocene ( $\mathrm{MH} \sim 8.3 \mathrm{ka}$ ), (D) Early Holocene (EH 11.7 ka), (E) Last Glacial Maximum (LGM 23 ka), Last Interglacial (LIG $120 \mathrm{ka})$.

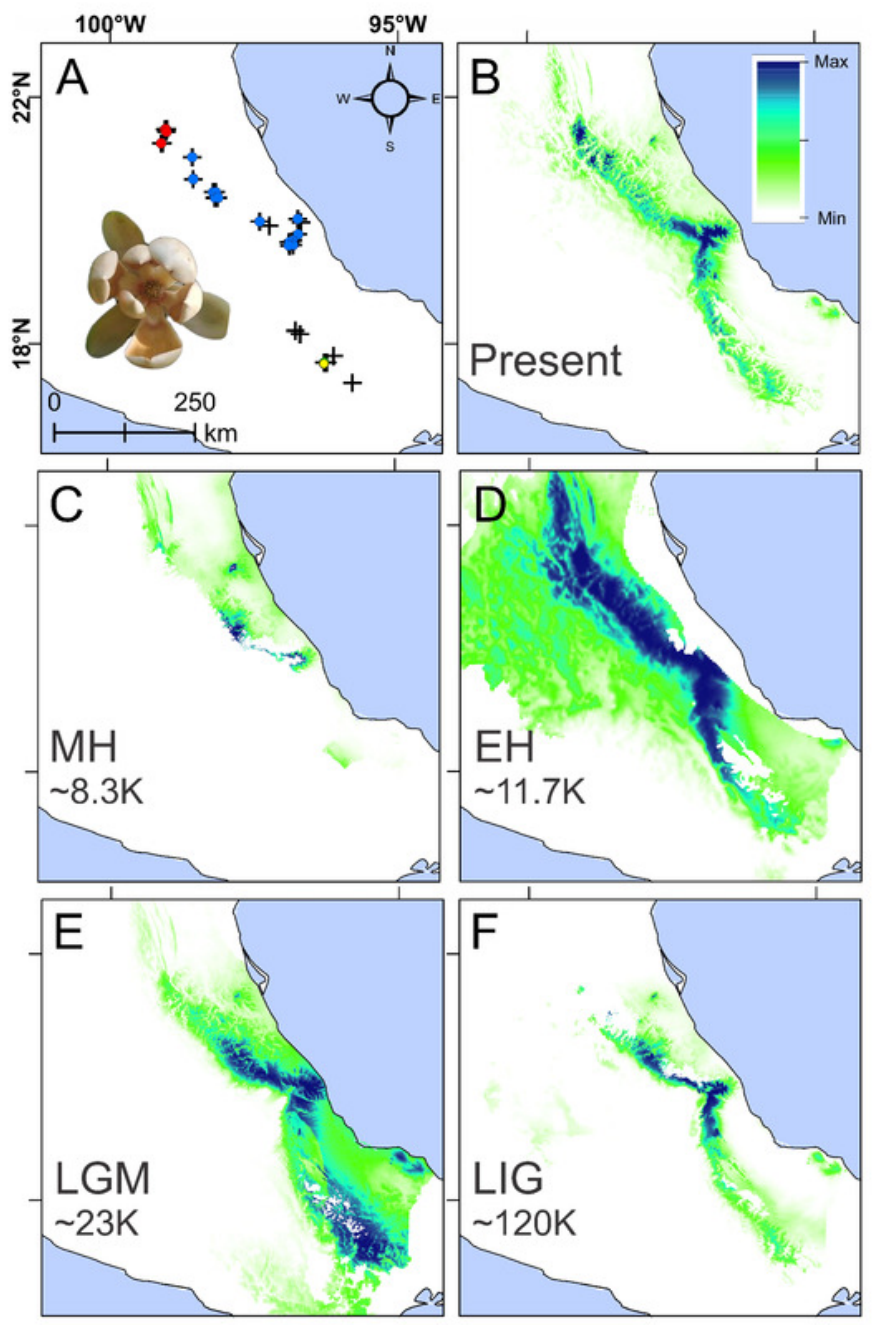

